SOCIO-DEMOGRAPHIC STATUS

\title{
Socio-Demographic Status: Theory, Methods and Applications
}

\author{
Kabir Bindawa Abdullahi \\ Umaru Musa Yar'adua University, Katsina, Nigeria \\ Email: kabir.abdullahi@umyu.edu.ng
}

\begin{abstract}
Our socio-demographic status is determined by socio-demographic position and success. In the theoretical frame works, little was known about the theory, quantification and evolutionary mechanism of socio-demographic status of individual(s). This paper proposed theoretical assumptions for the evolution of socio-demographically unique population. Seven (7) factors (the driving forces) and eight (8) conditions responsible for the evolution of socio-demographically unique population were identified and explained. The evolutionary transitions were organized into six (6) socio-demographic ranks. The paper also identifies the basic features that clarify our understanding about the conception of socio-demographic status of an individual(s) as common, universal and desirable positions, achievements, and advantages every individual strives and competes to attain, achieve and maintain which are determined by biological and social environments, driven and regulated by a continuum of competitions. The paper presents a new dimension for the quantitative assessment of an individuals' socio-demographic status and the established hierarchical transitions.
\end{abstract}

Keywords: Socio-demographic positions; Socio-demographic success; Sociodemographic evolution; Socio-demographic hierarchy; Mechanism; Quantitative Assessment. 
SOCIO-DEMOGRAPHIC STATUS

\section{Introduction}

In our daily life, we proud to compete within the social environment because of the social positions and successes we have attained. In an academic, occupational, and family structure, we proud of our socio-demographic profiles (status). Likewise, different social communities and societies proud for their individual's socio-demographic profiles. which are indicators of their socio-economic development.

When we think of our socio-demographic characteristics, we think of what social attributes and elements (e.g education, occupation, family structure), and advantages are essential for us to competes and acquire. We also reflect what biological and demographic advantages (e.g gender and age) we have acquired in our life and survival. Each of us competes for socio-demographic advantages with varying speeds. Our speed to for the attainment of highest socio-demographic status (socio-demographic position and success) are controlled and regulated by biological and social competitions, and also influenced by the biological and social environments. This competitive regulation and influences of biological and social environments result to the evolution of socio-demographically unique population of individuals. Demographers, sociologist, social psychologist and evolutionary biologist are highly interested in the mechanism responsible for these socio-demographic changes in a population of individuals.

In research, socio-demographic characteristics of a population or individual have been essentially investigated to provide a correlated understanding about a certain phenomena. For instance, in medical research, lifestyle diseases, disease occurrences, diseases severity, and disease susceptibility are correlated with socio-demography (Trent \& South, 1992; Ramirez et al., 1993; Kravdal, 2002; Skrzypczak, 2009; Bai et al., 2015). However, it is a philosophical tradition for every research in social population must be accompanied by a socio-demography (Thomas et al., 2006). Despite this philosophy, judgment about population or individual's sociodemographic characteristics is based on frequencies and percentages, odd ratio, cluster statistics are usually used. Higher and advanced statistical analyses (such as ANOVA and its counterpart nonparametric approaches) are impossible because: (a) suitable sociometric analysis is inaccessible to cumulate the results of all socio-demographic attributes into a one meaningful 
SOCIO-DEMOGRAPHIC STATUS

result, thus the socio-demographic attributes in question are correlated and presented separately, (b) it is difficult to be express the result as per-respondent. Moreover, the literal and theoretical meaning of what socio-demographic status refers from dictionaries and theoretical works have not presented a clear theoretical explanations and methodological quantification. Furthermore, even the well established social theories of Karl Marx, (1959) and Max Weber (1921/2015) about social hierarchy and status was based on one or two attributes (such as prestige, power, dominance, materialism, productivity, occupation or skills) and has no clear quantitative guidelines.

This paper attempts to provide basic features of quantitative socio-demography (sociodemographic status) and how the various socio-demographic attributes and elements are interrelated, correlated and quantified.

\section{Socio-demographic Status: The General Features}

- Socio-demographic status refers to the sociological and demographic attributes acquired by an individual(s) in a population that determine his/her socio-demographic positions or niches, socio-demographic roles, and as well as the correlating socio-demographic advantages he/she attains and succeeds. It informs us about the socio-demographic profile of an individual(s).

- Socio-demographic status is a motivational construct. It comprised of common, universal and desirable positions, achievements, and advantages every individual strives and competes to attain, achieve and maintain. The commonality and universality nature of socio-demographic status distinguishes it from race, ethnicity, religiosity, urbanization, geographical location, materialism, and social power.

- Socio-demographic status transcends a specific attribute. It integrates severally universal attributes common to all people (such as education, occupation, family and others) and common to all populations (such as gender and age).

- Socio-demographic attributes are ordered and ranked by acquisition and advantage respectively relative to others. The acquisition of socio-demographic attributes follows an ordered system one upon the other over a time. Within each acquired attribute there exists a varying degrees of elements (advantages) ordered in a continuum of ranks. 
First acquired attribute: age (elements: childhood, adolescent and adulthood) $\rightarrow$ second acquired attribute: education (elements: basic/student, post basic/teacher, tertiary/researcher) $\rightarrow$ third acquired attribute: occupation (elements: lower class, middle class and higher class) $\rightarrow$ fourth acquired attribute: family (elements: separated/divorced, widow and married).

The number of elements within each attribute depends on the social construct of the population, and the categories established. Each element represents an order of acquired advantage relative to the other elements. These elements are created by continuum of competition (through genetic competition $\rightarrow$ physiological competition $\rightarrow$ Demographic competition $\rightarrow$ psychosocial competition).

- Socio-demographic status is biologically and socially (i.e biological and social environments) acquired and controlled in a systematic and hierarchical order of interrelated elements. Such an elements form the basis of variability within each sociodemographic attributes.

Gender is biologically acquired. Age is acquired by the combination of biological and social environments. Education, occupation and family are all acquired in a social environment.

- Socio-demographic status determines the socio-demographic position (social configuration) and socio-demographic success (socio-demographic score) what identifies socio-demographic uniqueness (mechanism through the continuum of competitions $\rightarrow$ genetic selection $\rightarrow$ physiological selection $\rightarrow$ demographic selection $\rightarrow$ psychosocial selection $\rightarrow$ psychosocial fitness $\rightarrow$ socio-demographic evolution) of an individual(s). Socio-demographic position and socio-demographic success are two correlating factors that define social status of an individual(s). 
SOCIO-DEMOGRAPHIC STATUS

\section{Determinants of socio-demographic status}

\section{A. Socio-demographic Position (SDP)}

Socio-demographic positions refer to the common, universal and desirable social niches and roles everyone is competing and striving to attain and acquire in a social structure. It informs us about the socio-demographic position and role of an individual(s) regardless of the degree of his/her success. For instance, one might desire to become an emirate professor, a consultant engineer, a consultant medical doctor, a businessman, a permanent secretary, a great grandfather/mother of his/her children, or hope to attain a combination of some of these positions, within a competitive population regardless of whether he/she made a significant achievements relate to that position.

\section{Measurement of socio-demographic position}

Socio-demographic configurations (SDc). It expresses the socio-demographic niches and roles of an individual(s) in a population. The assessment of socio-demographic configuration requires an empirical data collected by an established questionnaire. The collected data is then organized, ranked based on the degree of advantage acquired from a set of socio-demographic elements in each socio-demographic attributes. The socio-demographic element's rank number is then sociometrically analyzed using Kab's multiple factor analysis (Abdullahi, 2019) to obtain the configuration result.

Instrument for Data Collection. Structured questionnaire is used in this case. The items of the questionnaire should present the appropriate selection of the common and universal sociodemographic attributes and their elements. Figure 1 and 2 provided a sample of a questionnaires that can be used. 
SOCIO-DEMOGRAPHIC STATUS

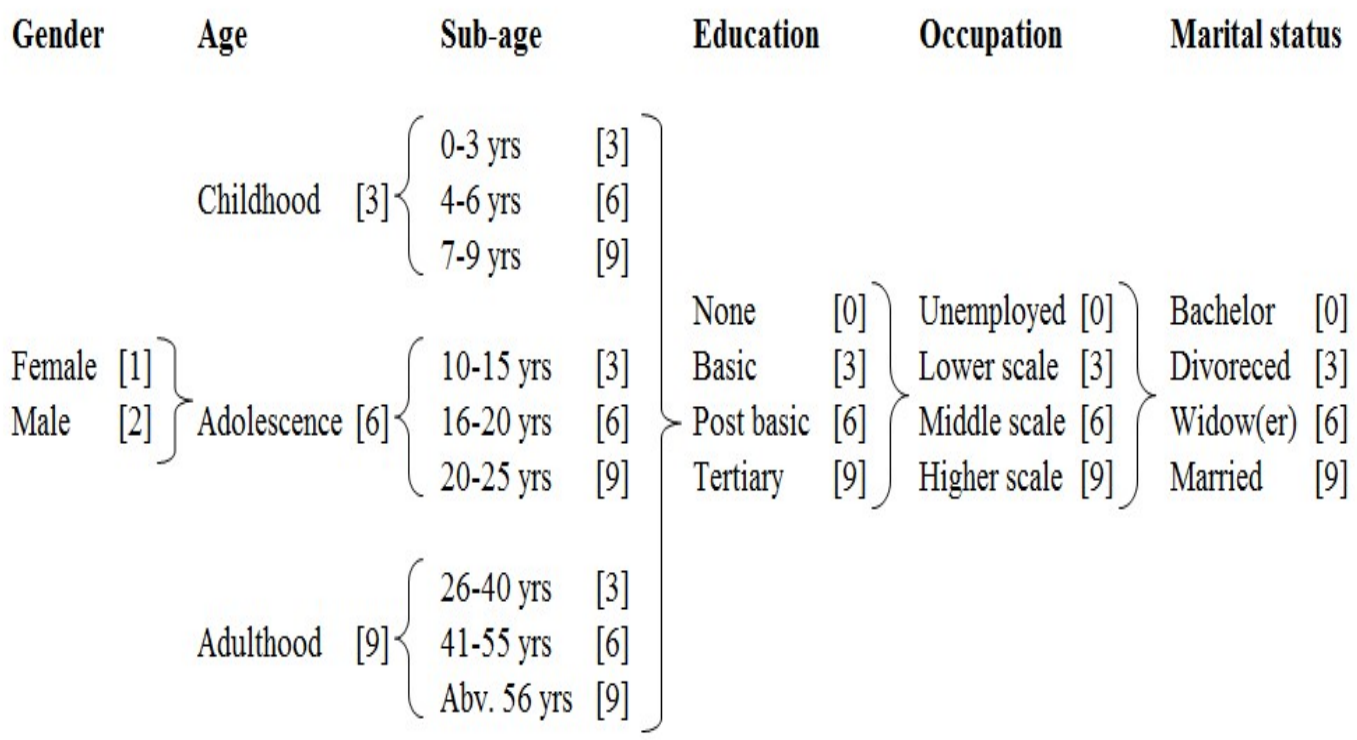

Figure 1: Showing a sample of questionnaire instrument for quantitative determination of common socio-demographic position

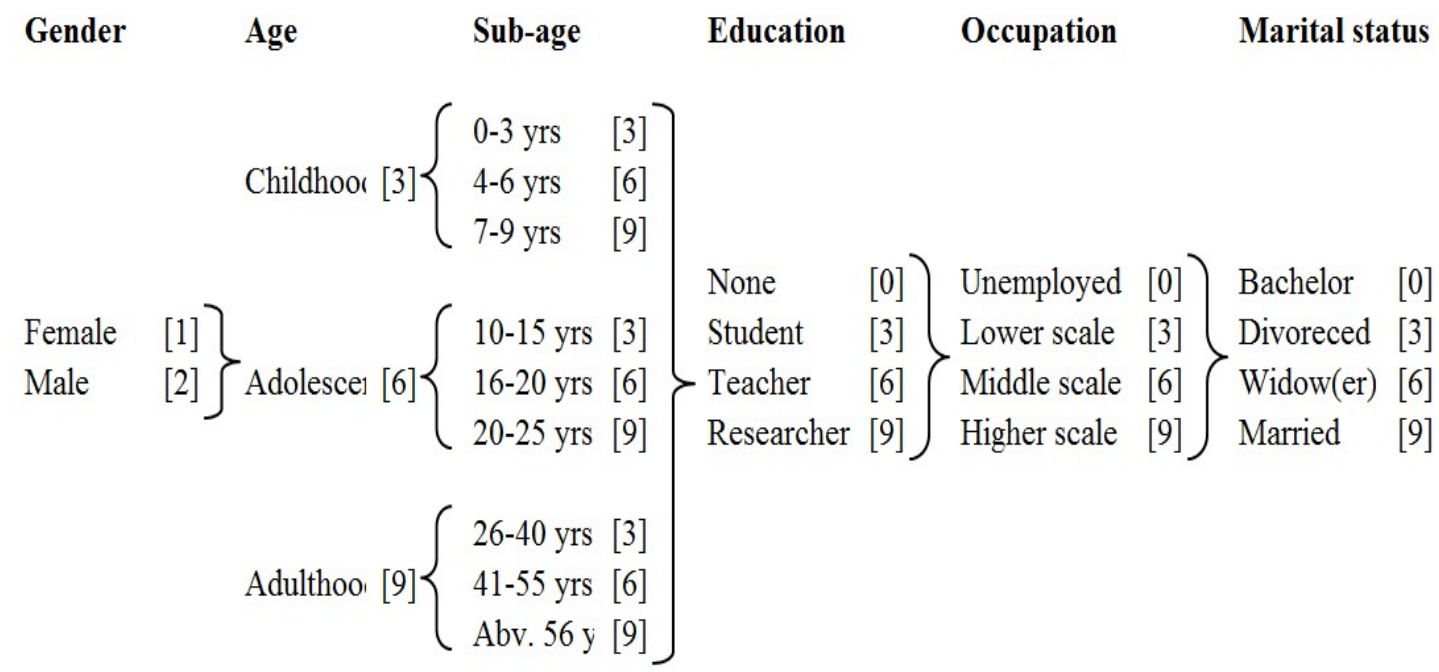

Figure 2: Showing a sample of questionnaire instrument for quantitative determination of common socio-demographic position 
SOCIO-DEMOGRAPHIC STATUS

Instrument for Sociometric Data Analysis. Due to the consideration for multiple sociodemographic attributes, Kab's multiple factor analysis (Abdullahi, 2019) can be used to calculate the socio-demographic configuration. It is expressed by equation (1) and (2) as follow:

$$
S D c=\left(\frac{F S E R N}{1}+\frac{S S E R N}{10}+\frac{T S E R N}{100}+\ldots \ldots \ldots \frac{x S E R N}{10^{y}}\right)-1
$$

If socio-demographic attribute is uncommented by gender involved, the equation become

$$
S D c=\left(\frac{F S E R N}{1}+\frac{S S E R N}{10}+\frac{T S E R N}{100}+\ldots \ldots \ldots \frac{x S E R N}{10^{y}}\right)
$$

Where:

$y=(0,1,2,3, \ldots \ldots)$

$S D c=$ Socio-demographic configurations.

FSERN = Socio-demographic element's rank number of the first acquired attribute.

SSERN = Socio-demographic element's rank number of the second acquired attribute.

$T S E R N=$ Socio-demographic element's rank number of the third acquired attribute.

$x S E R N=$ Last socio-demographic element's rank number of the last acquired attribute.

Note: The determination of a specific socio-demographic element's rank number $x S E R N$ requires a simple ranking as described by Kab's multiple factor analysis (Abdullahi, 2019). A specific attribute (e.g gender, or any others) can be uncommented (i.e eliminate or ignore its role as a source of variability within) without altering the pattern, order, system, hierarchy, and rules. For instance, 2.9639 of a male socio-demographic position can be uncommented by gender, or family attribute to 0.9639 or 2.9630 respectively.

Result of Sociometric Data Analysis. The socio-demographic configuration of an individual(s) is not to be approximated, because each digit of the configuration represents a particular attribute. The number of digits determines the number of socio-demographic attributes an individual acquired, and differences in each digit over others represent a variation within the individuals in the population. If the first digit of the SDc result is uncommented (i.e gender), higher SDc shows higher the social advantage, position, and role.

Further Statistical Analysis. It is possible to run a number of statistical analysis such MANOVA and other alternate non-parametric methods because the result can be calculated per individual. The per-respondent result provides analysis of variation that exists between 
SOCIO-DEMOGRAPHIC STATUS

individuals in a given sampled population. Other factors such as race, ethnicity, religiosity, urbanization, geographical location, materialism, and value system can be considered as a source of variation between populations. Statistical analysis provides hallmark evidence upon which generalization can be made.

\section{B. Socio-demographic Success (SDS)}

Socio-demographic success refers to the common, universal and desirable social achievements, victories, triumphs everyone is competing and striving to attain and acquire in a social structure. It informs us about the socio-demographic achievements of an individual(s) regardless of his/her position(s). For instance, one might desire to become the most successful professor, the most successful engineer, the most successful medical doctor, the most successful businessman, the most successful civil servant, and etc, within a competitive population regardless of his/her socio-demographic positions.

\section{Different forms of socio-demographic success}

Depending on the social specification of a given population, the following sociodemographic successes can be evaluated.

i. Common socio-demographic success. In general socio-demographic structure. This applied to all individuals. It is a general and common approach irrespective of one expertise (Refer to figure 3 and 4). For a guided example of questionnaire approach and the ranking of its socio-demographic elements.

ii. Academic socio-demographic success. Socio-demographic success in an academic structure and environment (Refer to figure 5). For a guided example of questionnaire approach and the ranking of its socio-demographic elements.

iii. Business socio-demographic success. Socio-demographic success in a business structure and environment (Refer to figure 6). For a guided example of questionnaire approach and the ranking of its socio-demographic elements.

iv. Occupational socio-demographic success. Socio-demographic success in an occupational structure and environment (Refer to figure 7). For a guided example of questionnaire approach and the ranking of its socio-demographic elements. 
SOCIO-DEMOGRAPHIC STATUS

v. Family socio-demographic success. Socio-demographic success in a family structure and environment (Refer to figure 8). For a guided example of questionnaire approach and the ranking of its socio-demographic elements.

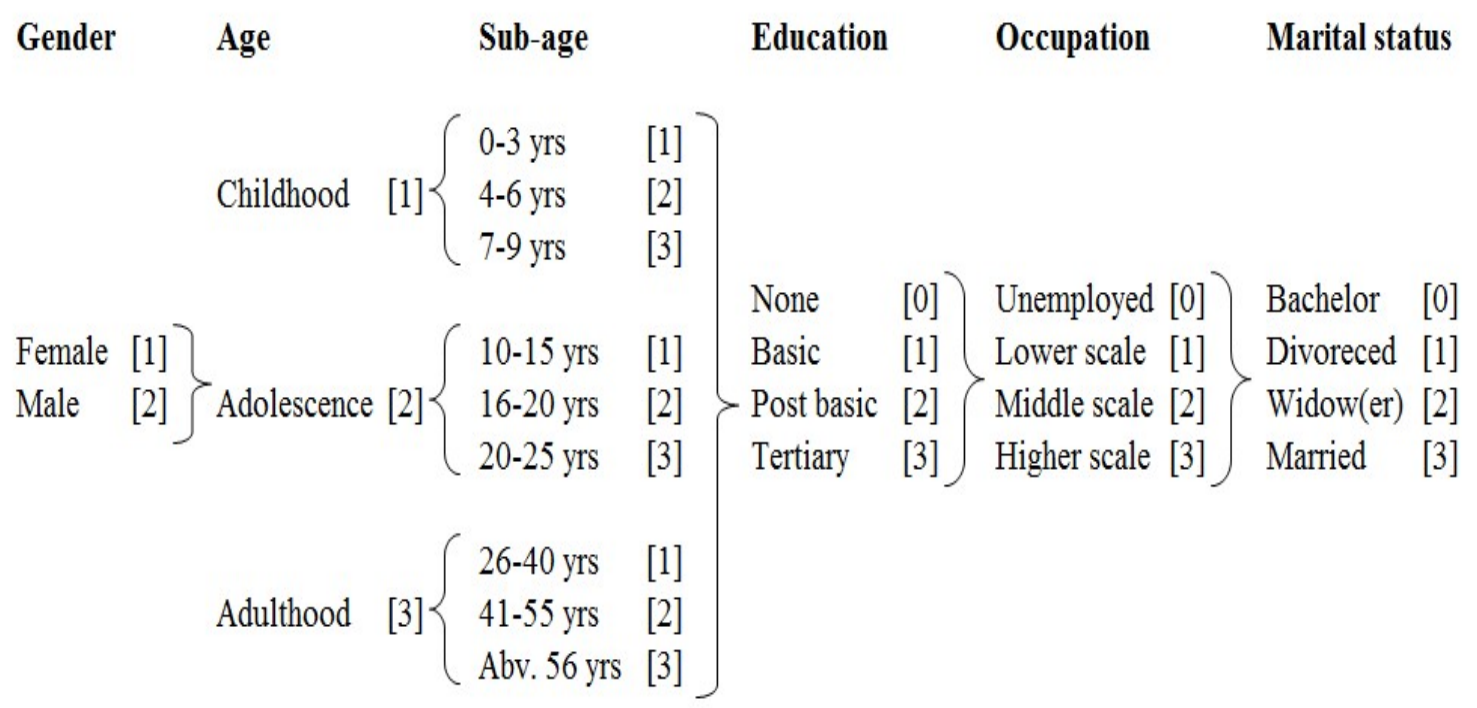

Figure 3: Showing a sample of questionnaire instrument for quantitative determination of common socio-demographic success

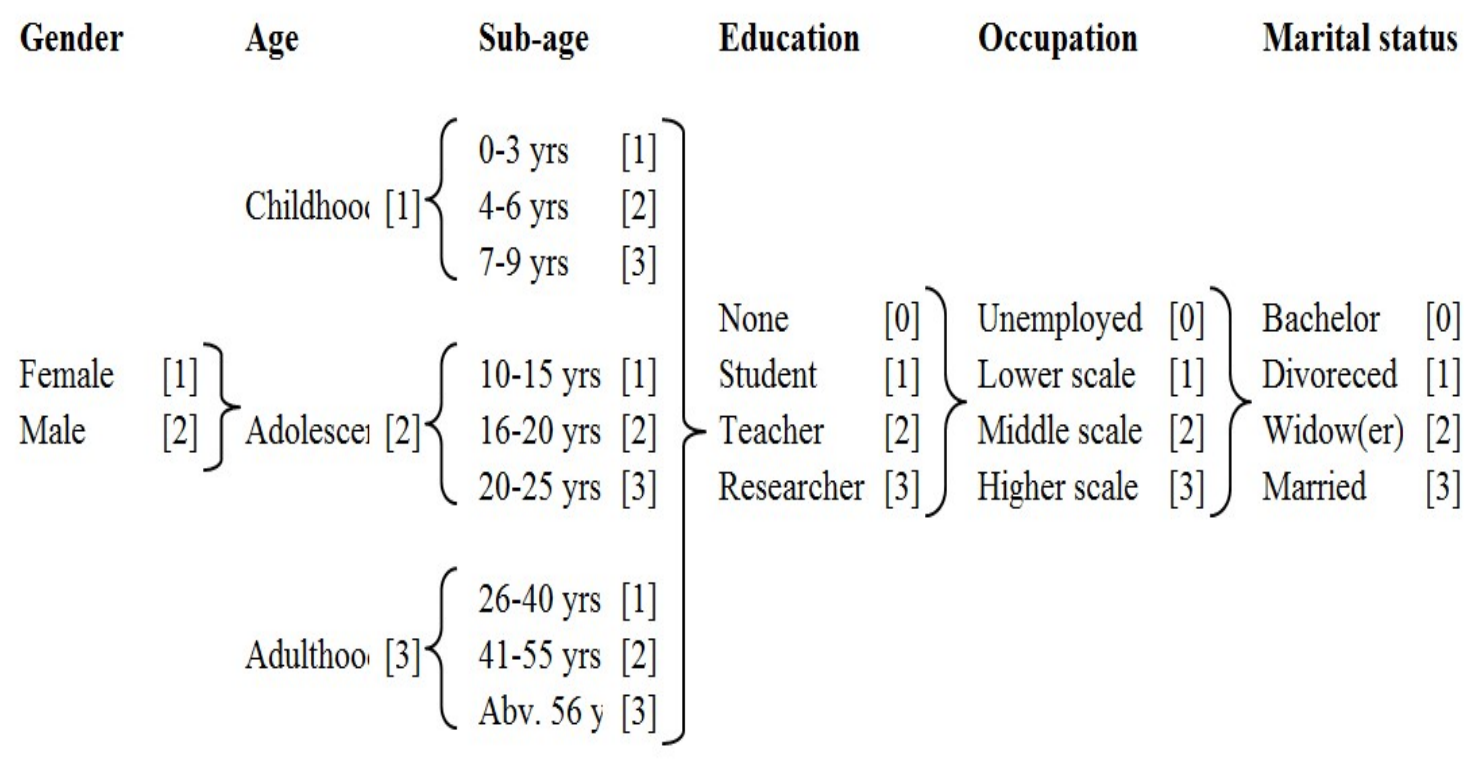

Figure 4: Showing a sample of questionnaire instrument for quantitative determination of common socio-demographic success 
SOCIO-DEMOGRAPHIC STATUS

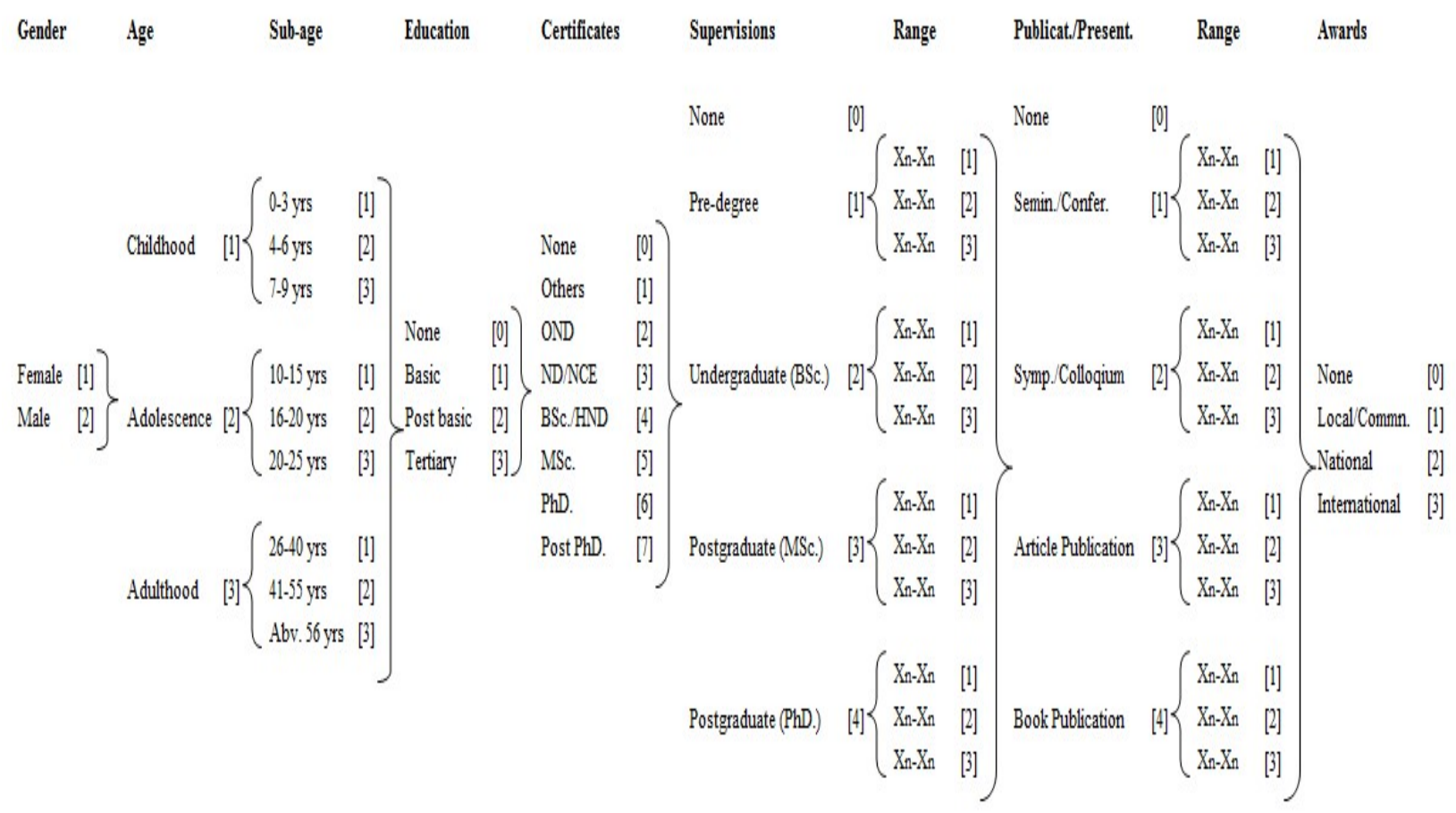

Figure 5: Showing a sample of questionnaire instrument for quantitative determination of academic socio-demographic success

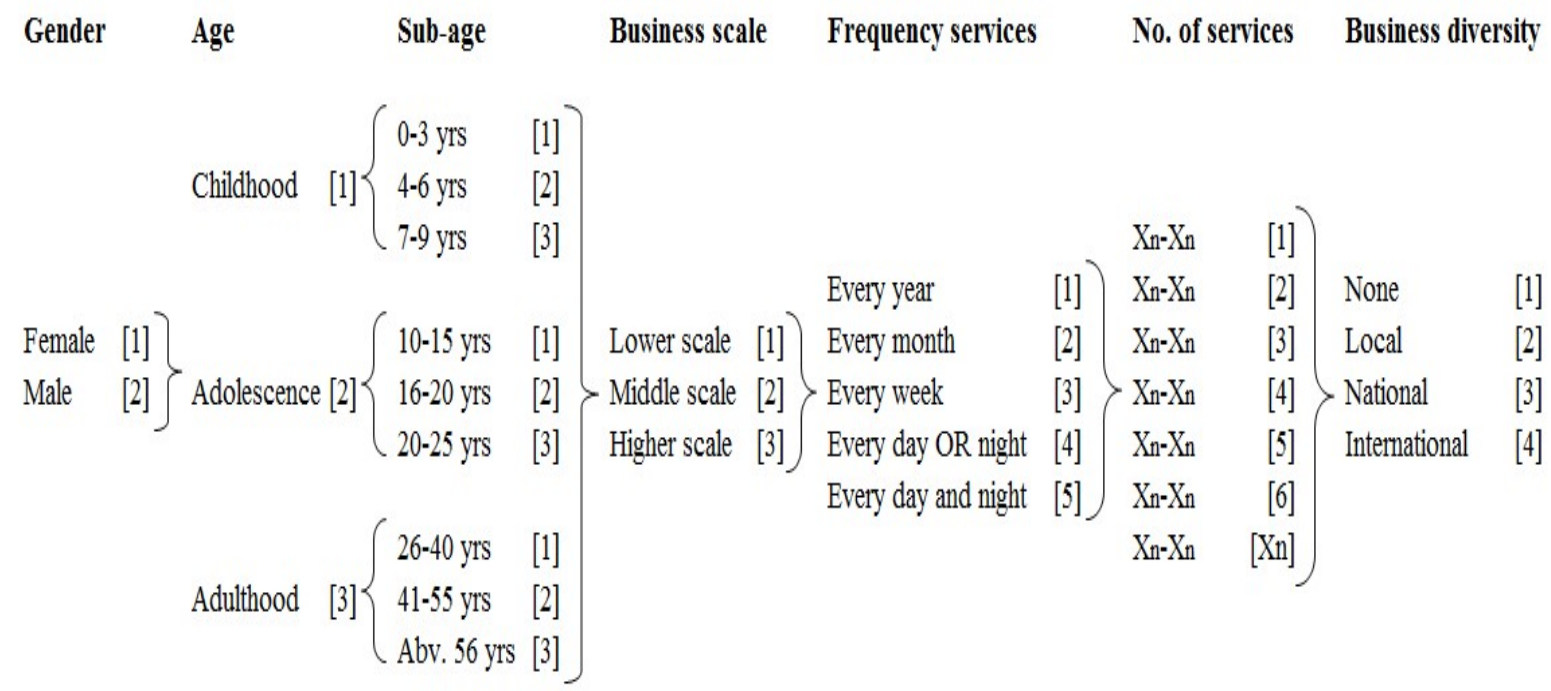

Figure 6: Showing a sample of questionnaire instrument for quantitative determination of business socio-demographic success 
SOCIO-DEMOGRAPHIC STATUS

\begin{tabular}{|c|c|c|c|c|c|c|c|c|}
\hline \multirow[t]{2}{*}{ Gender } & \multirow[t]{2}{*}{ Age } & \multicolumn{2}{|l|}{ Sub-age } & Year of service & \multicolumn{2}{|c|}{ Grade level } & \multicolumn{2}{|c|}{ Appointment } \\
\hline & & $0-3$ yrs & 1 & $\mathrm{Xn}_{\mathrm{n}-\mathrm{Xn} \text { yrs }} \quad[1]$ & $\mathrm{X}_{1}$ & [1] & $\mathrm{X}_{1}$ & \\
\hline & Childhood [1] & $4-6$ yrs & {$[2]$} & Xn-Xn yrs $\quad[2]$ & $\mathrm{X}_{2}$ & {$[2]$} & $\mathrm{X}_{2}$ & \\
\hline & & $7-9 \mathrm{yrs}$ & [3] & Xn-Xn yrs & $\mathrm{X}_{3}$ & [3] & $\mathrm{X}_{3}$ & \\
\hline & & & & Xn-Xn yrs & $\mathrm{X}_{4}$ & [4] & $X_{4}$ & \\
\hline emale [1] & & $10-15 \mathrm{yrs}$ & [1] & $X_{n}-X_{n} y r s$ & $X_{5}$ & {$[5]$} & $\mathrm{X}_{5}$ & \\
\hline le $[2]$ & Adolescence [2] & $16-20 \mathrm{yrs}$ & [2] & $>\mathrm{Xn}-\mathrm{Xn}$ yrs & $X_{6}$ & [6] & $X_{6}$ & \\
\hline & & $20-25 \mathrm{yrs}$ & [3] & Xn-Xn yrs & $X_{7}$ & [7] & $\mathrm{X}_{7}$ & \\
\hline & & & & Xn-Xn yrs & $\mathrm{X}_{8}$ & {$[8]$} & $\mathrm{X}_{8}$ & \\
\hline & & $26-40 \mathrm{yrs}$ & [1] & Xn-Xn yrs & X9 & [9] & X9 & \\
\hline & Adulthood [3] & $41-55 \mathrm{yrs}$ & [2] & Xn-Xn yrs $\quad[10]$ & $\mathrm{X}_{10}$ & [10] & $\mathrm{X}_{10}$ & \\
\hline & & Abv. 56 yrs & [3] & $\mathrm{Xn}$-Xn yrs $\quad\left[\mathrm{Xn}_{n}\right]$ & $X_{n}$ & {$\left[X_{n}\right]$} & $\mathrm{X}_{\mathrm{n}}$ & \\
\hline
\end{tabular}

Figure 7: Showing a sample of questionnaire instrument for quantitative determination of occupational socio-demographic success

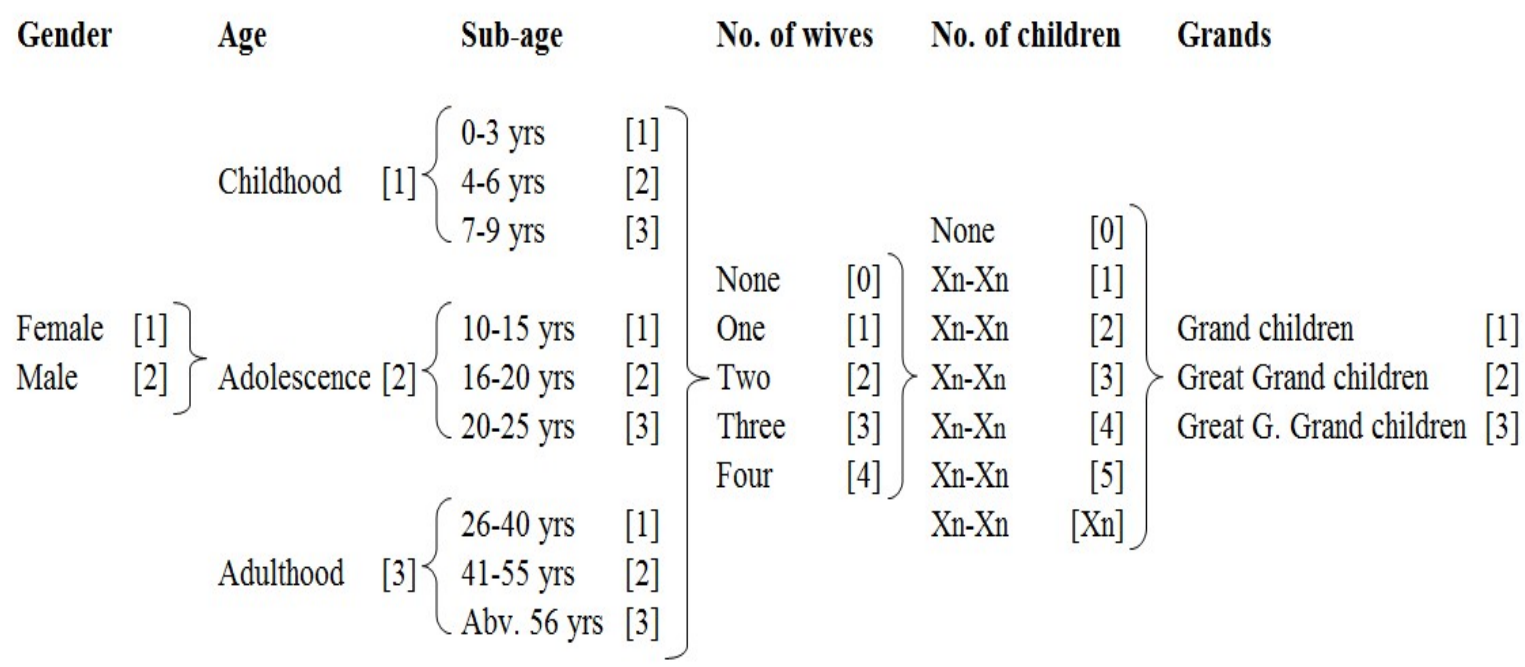

Figure 8: Showing a sample of questionnaire instrument for quantitative determination of family socio-demographic success 
SOCIO-DEMOGRAPHIC STATUS

\section{Measurement of socio-demographic success}

Socio-demographic score (SDs). It expresses the measure of the socio-demographic achievements of an individual(s) in a socially specified population. The assessment of sociodemographic score requires an empirical data collected by an established questionnaire. The collected data is then organized, ranked based on the degree of achievements acquired from a set of socio-demographic elements in each socio-demographic attributes. The socio-demographic element's rank(s) number is then sociometrically analyzed using a new approach here presented to obtain the socio-demographic score.

Instrument for Data Collection. Structured questionnaire is used in this case. The items of the questionnaire should present the appropriate selection of the common and universal sociodemographic attributes and their elements. Figure 3-9 provided a sample of questionnaires that can be used. The distinction between this questionnaires and that use in SDP assessment is that, the number and the description of elements for a particular socio-demographic attribute varies and more specific, elaborated respectively. It also selects only one social attributes. More than one element can be considered as acquired advantages and is also considered in the sociometric calculations.

Instrument for Sociometric Data Analysis. A new method is proposed here to calculate the socio-demographic score of an individual(s) in a population. It is expressed as the powered sum of socio-demographic ranks of all the socio-demographic attributes acquired by the individual in a socially specified population. It is expressed by equation (2) as follow:

$$
S D s=(F S E R N)^{0}+(F S E R N)^{1}+(F S E R N)^{2}+(F S E R N)^{x}
$$

Where:

$x=(0,1,2, \ldots \ldots .$.

$S D s=$ Socio-demographic score

FSERN = Socio-demographic element's $\operatorname{rank}(\mathrm{s})$ number of the first acquired attribute.

SSERN = Socio-demographic element's rank(s) number of the second acquired attribute.

$T S E R N=$ Socio-demographic element's rank(s) number of the third acquired attribute.

$x S E R N=$ Last socio-demographic element's $\operatorname{rank}(\mathrm{s})$ number of the last acquired attribute. 
SOCIO-DEMOGRAPHIC STATUS

Note: The determination of a socio-demographic element's $\operatorname{rank}(\mathrm{s})$ number $x S E R N$ requires a simple ranking without intervals and limitation. The lack of interval and limitation is what distinguishes this method of ranking that that used in Kab's multiple factor analysis. A specific attribute or sub-element (e.g gender, or any others) can be uncommented (i.e eliminate or ignore its effect as a source of variability within) without altering the pattern, order, system, hierarchy, and rules.

Result of Sociometric Data Analysis. The higher SDs shows higher social achievement and success in a socially specified population.

Further Statistical Analysis. It is possible to run a number of statistical analysis such MANOVA and other alternate non-parametric methods because the result can be calculated per individual. The per-respondent result provides analysis of variation that exists between individuals in a given sampled population of a specific expertise. Other factors such as race, ethnicity, religiosity, urbanization, geographical location, and value system can be considered as a source of variation between populations. Statistical analysis provides hallmark evidence upon which generalization can be made.

\section{Mechanism of Socio-demographic Evolution}

The mechanism for the evolution of socio-demographic positions and successes of an individual(s) which identifies socio-demographic uniqueness is explained by two theoretical assumptions. Socio-demographic uniqueness results to the evolution of new socio-demographic population. What the issue socio-demographic evolution is trying to explain the mechanisms that drives and links population biology, demography, and social structure.

First Theoretical Assumption. It states that when a nature selects an individual(s) from competing environments, he/she receives the most influence and the most advantages from the biological and social environments that prepare him/her socially and psychologically fit for the attainment and achievement of different status of socio-demographic positions and successes with a varying speeds and degrees of uniqueness.

In common social phenomena, social success is related to age and time (ref.....). But biologically and environmentally advantaged (socially selected) individual(s) would move the 
SOCIO-DEMOGRAPHIC STATUS

fastest speed to reach that target socio-demographic transition everyone is striving to attain, achieve and maintain. The mechanism of social uniqueness is driven and regulated by the seven (7) forces which follow this order:

Competitions $\rightarrow$ Genetic selection $\rightarrow$ Physiological selection $\rightarrow$ Demographic selection $\rightarrow$ Psychosocial selection $\rightarrow$ Psychosocial fitness $\rightarrow$ Socio-demographic evolution

Competition. The competitions; whether genetic, physiological, demographic, and psychosocial; for the acquisition of genetic, physiological, demographic, and psychosocial advantages; is a principal force that creates different socio-demographic elements and drives genetic selection, physiological selection, demographic selection, and psychosocial selection toward psychosocial fitness and socio-demographic evolution. For instance, gender acquisition is a result of genetic competition between $\mathrm{X}$ and $\mathrm{Y}$ gametes. If $\mathrm{X}$ gamete outcompetes gender would be female, and if $\mathrm{Y}$ gamete outcompetes male offspring is the gender. Competition for existence and survival creates different ages and life expectancy. Competition for educational positions and success creates different educational levels and requirements for admission and graduation. Competition for family (a mating partner) and territory creates different values.

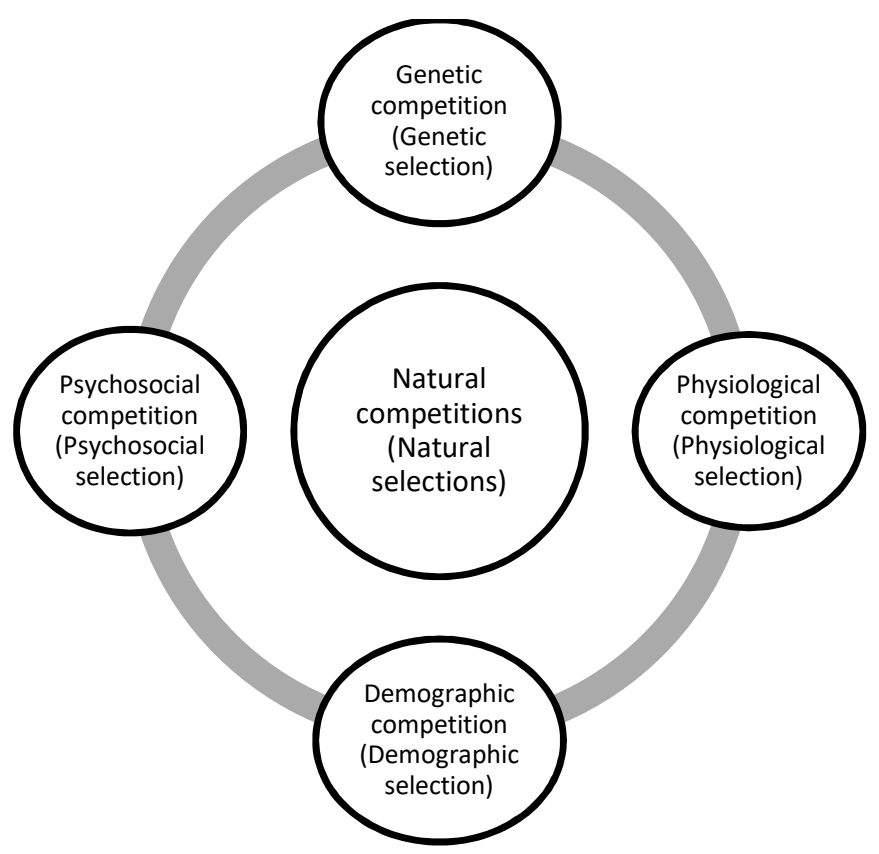

Figure 9: Showing the role of continuum competitions as a driving force of natural completions and selections 
SOCIO-DEMOGRAPHIC STATUS

Natural (biological) selection. Competitions for genetic and physiological advancement, specialization and advantages drive the idea of natural selection. The biological environment comprised of factors that favors an organism to outcompete the genetic chances and the physiological regulatory requirements. The desirable traits acquired together with optimum physiological states accelerates the development and proper functioning of body organs and hormonal and nervous coordination which influences behaviors, cognitive responses, and adaptive potentials of the organism. Naturally selected organisms would tend to grow and develop faster with high sense of maturation, adaptation and behaviors. Together with the cognitive responses would help him/her to pass the requirements of social and psychological environments.

Genetic selection. Competition for desired alleles, genes, traits, gametes, and beneficial mutations necessitates for sexual selection, sexual selection and mating structure, genetic drift, and genetic purity (free from harmful mutations). The outcompeted individuals are naturally selected.

Physiological selection. Competition for hormonal and nervous coordination and adaptation (for accelerated development, maturation, cognitive responses, and neural mechanisms) necessitates for the acquisition of desirable genetic traits and biological requirements. The outcompeted individuals are naturally selected.

Demographic selection. Competition for existence and survivals necessitates for freedom of fundamental rights, healthy lifestyles, immunity, defensive and adoptive mechanisms, nutrition, and parental care. The outcompeted individual(s) are naturally selected and favored by good social, political, economic, and religious policies of their immediate environment.

Psychosocial selection. Competition to satisfy, adopt and tolerate the social and psychological requirements and challenges in different social environments (e.g educational, occupational and family structures) creates the issue of psychosocial selection. Competition for: (a) highest academic and educational positions and advantages necessitates for the requirement of maturation and cognitive responses. The outcompeted individuals are those with highest commitments, dedication, good personalities, cognitive creativity and constructivity; (b) highest 
SOCIO-DEMOGRAPHIC STATUS

occupational positions and advantages necessitates for the requirement of maturation, cognitive responses, education or skills, commitments, dedication, and good personalities. The outcompeted individuals are those with the highest creativity and constructivity; (c) mating partner(s) and happy family necessitates for the requirement of maturation, cognitive responses, education, skills, occupation, commitments, dedication, good personalities, and desirable social and biological traits. The achievement and success remains variable to the value system.

Note that, the idea of social materialism arose due to reaching a certain positions and successes through the occupational advantages (such as incomes, turnover, salaries, wages and etc). The more the occupationally successful an individual has become, the more the chances he/she has to acquires and possesses a relative degree or amount of material objects and wealth (such as assets and liabilities).

Psychosocial fitness. His/her ability to perform to the desired requirements and expectations of social and psychological environments scale him/her to acquire the diverse range of social advantages, positions with highest speed and successes.

Socio-demographic evolution. This is the highest status every individual is striving to attain, achieve and maintain. Over time, the accumulation of such individuals would transform the social environment into a new distinct and unique population.

Second Theoretical Assumption. It state that, the socio-demographic status (positions and successes) of individual(s) in a population remains socio-demographically dynamic provided that there is population growth, continuum of competitions, genetic selection, physiological selection, demographic selection, psychosocial selection, migration, and immigration.

Population growth. It ensures continues existence of socially dynamic population of individuals;

Migration. It exposes, transforms and upgrades the individuals with new genetic and social traits;

Immigration. It introduces new genetic and social traits into the social population. 
SOCIO-DEMOGRAPHIC STATUS

\section{Evolutionary Transitions of Socio-demographic Hierarchy}

This section describes the different evolved socio-demographic hierarchy of individuals in a population. It present and clarify our understanding about the social hierarchy and the quantitative basis for its establishment.

Suppose we consider the general approach of socio-demographic quantification (sociodemographic position and socio-demographic success) as demonstrated in Figure 1 or 2 and Figure 3 or 4 to establish a common socio-demographic hierarchy in a population of all female (or male) individuals. We can identify the following hierarchical structure (Figure 10): two (2) socio-demographic kingdoms (feminine and masculine kingdom), within each sociodemographic kingdom with three (3) socio-demographic clade (first, second and third clade), within each socio-demographic clade with three (3) socio-demographic groups (first triage upper, middle and lower groups), within each socio-demographic group with four (4) sociodemographic classes (class 1 to 4), within each socio-demographic class with four (4) sociodemographic orders (order 1 to 4 ), within each socio-demographic order with four (4) sociodemographic grades (grade 1 to 4 ).

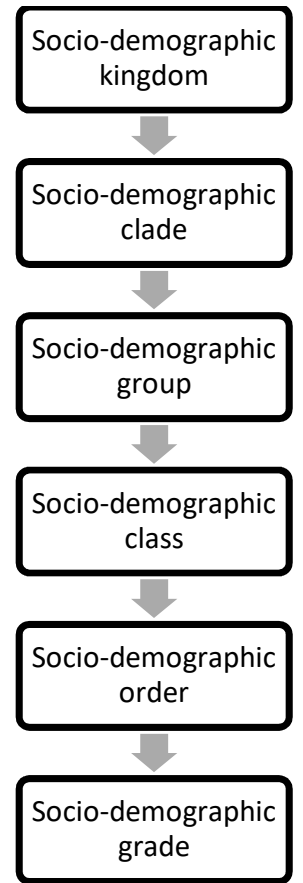

Figure 10: Showing the ranks of socio-demographic hierarchy 
SOCIO-DEMOGRAPHIC STATUS

\section{Socio-demographic hierarchy}

Socio-demographic kingdoms. Is the first rank of the socio-demographic hierarchy. It connects all age individual males and females irrespective of their educational, occupational attainments, and family acquisition. The main central goal of their interaction is the shared completion for gender. Based on this gender differences, socio-demographic clade is categories as feminine kingdom and masculine kingdom comprising of all female and male individuals respectively.

Socio-demographic clades. Is the second rank of the socio-demographic hierarchy. It connects all female or male individuals of all ages irrespective of their educational, occupational attainments, and family acquisition. The main central goal of their interaction is the shared completion for existence and survival. Socio-demographic clade is seen in three categories as follows:

Third clade (third triage). This socio-demographic clade comprised of adult individuals of all ages that share a common but relatively different intensity of competing social advantages. The clade members mostly share common social click and struggles to attain, acquire, update, upgrade maintain their social positions and successes (such as education, occupation and family). Although they live in same social niches and may have differences in socio-demographic success, but usually structured themselves into distinct socio-demographic groups based on age (age mates) as third clade upper group (late aged adults), third clade middle group (middle aged adults), and third clade lower group (early aged adults). For evidence of quantitative representation and hierarchical demonstration, refer to appendix I.

Third clade upper group. Comprise of later aged adult individuals with usually high completion to maintain a specific social positions and advantages (Table 1). Similar with first triage middle and lower groups, the group members usually dissociate themselves into distinct socio-demographic classes, from class 1 to 4 . One socio-demographic class differs with the other based on the level of acquired education. Within each socio-demographic class, another distinction can be formed into different socio-demographic orders based on occupational scale. And with each socio-demographic order are other categories into different socio-demographic grades based on marital status. 
SOCIO-DEMOGRAPHIC STATUS

Table 1: Example of some features common among almost all individual of third clade group

\begin{tabular}{lcccc}
\hline Characteristics & Class 1 & Class 2 & Class 3 & Class 4 \\
\hline Level of education & Tertiary & Secondary & Basic & None \\
Struggle to maintain self and family status & $\checkmark$ & $\checkmark$ & $\checkmark$ & $\checkmark$ \\
Loss of job (or retirement) & $\checkmark$ & $\checkmark$ & $\checkmark$ & $\checkmark$ \\
Low income & $\checkmark$ & $\checkmark$ & $\checkmark$ & $\checkmark$ \\
Loss of family & $\checkmark$ & $\checkmark$ & $\checkmark$ & $\checkmark$ \\
Physical and mental degeneration & $\checkmark$ & $\checkmark$ & $\checkmark$ & $\checkmark$ \\
Medical complications & $\checkmark$ & $\checkmark$ & $\checkmark$ & $\checkmark$ \\
Menopause (for women) & $\checkmark$ & $\checkmark$ & $\checkmark$ & $\checkmark$ \\
\hline
\end{tabular}

Third clade middle group. Comprise of middle aged adult individuals with usually high completions to update/upgrade a specific social positions and advantages with usually almost same challenges (Table 2). Similar with first triage upper and lower groups, the group members usually dissociate themselves into distinct socio-demographic classes, from class 1 to 4 . One socio-demographic class differs with the other based on the level of acquired education. Within each socio-demographic class, another distinction can be formed into different sociodemographic orders based on occupational scale. And with each socio-demographic order are other categories into different socio-demographic grades based on marital status.

Table 2: Example of some features common among almost all individual of second clade group.

\begin{tabular}{lcccc}
\hline Characteristics & Class 1 & Class 2 & Class 3 & Class 4 \\
\hline Level of education & Tertiary & Secondary & Basic & None \\
Struggle to update/upgrade self and family status & $\checkmark$ & $\checkmark$ & $\checkmark$ & $\checkmark$ \\
Struggle for Job promotions, expansion or & $\checkmark$ & $\checkmark$ & $\checkmark$ & $\checkmark$ \\
diversification of skills & & & & \\
Struggle for more income & $\checkmark$ & $\checkmark$ & $\checkmark$ & $\checkmark$ \\
Stability of income & $\checkmark$ & $\checkmark$ & $\checkmark$ & $\checkmark$ \\
Physical and mental stress & $\checkmark$ & $\checkmark$ & $\checkmark$ & $\checkmark$ \\
\hline
\end{tabular}

Third clade lower group. Comprise of early aged adult individuals with usually high completions to attain a certain level of social positions and advantages and end at almost with same challenges (Table 3). Similar with first triage upper and middle groups, the group members also usually dissociate themselves into distinct socio-demographic classes, from class 1 to 4 . One 
SOCIO-DEMOGRAPHIC STATUS

socio-demographic class differs with the other based on the level of acquired education. Within each socio-demographic class, another distinction can be formed into different sociodemographic orders based on occupational scale. And with each socio-demographic order are other categories into different socio-demographic grades based on marital status.

Table 3: Example of some features common among almost all individual of third clade group

\begin{tabular}{lcccc}
\hline Characteristics & Class 1 & Class 2 & Class 3 & Class 4 \\
\hline Level of education & Tertiary & Secondary & Basic & None \\
Struggle to attain a certain level of & $\checkmark$ & $\checkmark$ & $\checkmark$ & $\checkmark$ \\
self and family status & & & & \\
Struggle for Job/skill acquisition & $\checkmark$ & $\checkmark$ & $\checkmark$ & $\checkmark$ \\
Struggle for income & $\checkmark$ & $\checkmark$ & $\checkmark$ & $\checkmark$ \\
instability of income & $\checkmark$ & $\checkmark$ & $\checkmark$ & $\checkmark$ \\
Physical and mental stress & $\checkmark$ & $\checkmark$ & $\checkmark$ & $\checkmark$ \\
\hline
\end{tabular}

Second clade (second triage). This socio-demographic clade comprised of adolescence individuals that share common competing social advantages and have almost same social challenges. The group members mostly share common social click and struggles to acquire and attain an educational status and skill. Adaptation and tolerance to social challenges represents the major common problems for most of the adolescents. At this point they recognize themselves as a unique socio-demographic group, obtain called classmates into second clade upper group (tertiary school classmates), second clade middle group (secondary school classmates) and second clade lower group (primary or elementary school classmates). In our recent sociodemographic transition, members of this clade, usually start competing for occupation or skills, but rarely competes for family. For evidence of quantitative representation and hierarchical demonstration, refer to appendix II.

First clade (first triage). This socio-demographic group comprised of child individuals that share a common competing biological and demographic advantages and have almost same challenges. The group members mostly share common social play ground and struggle to acquire and attain a certain sensory (ability: to recognize their environment, to hear, to feel etc) and nervous (ability: to walk, to speak, to learn and comprehend, to feed by self, and to become independent) responses. Unless there was any a genetic abnormality or error, the physiology would represent no challenge to them. However, the likely challenge they may face is the 
SOCIO-DEMOGRAPHIC STATUS

competition of their demographic environment (existence and survivals). At this point they recognize themselves as a unique group, obtain as age mates. In our recent socio-demographic transition, members of this clade neither compete for occupation nor for family. For evidence of quantitative representation and hierarchical demonstration, refer to appendix III.

\section{Population Socio-demographics}

Population socio-demographics describes the relationship that exist between individuals socio-demographic position against success and between the population's attributes (such as number of individuals against their attained socio-demographic position or success. It also defines the distribution of individuals based on their socio-demographic status in the general or specific or defined population (e.g population of smokers, drug adductors, criminals, HIV infected patients, hypertensive patients, etc).

The results in figure 11 explained the graphic relationship between socio-demographic position and success. The result shows that socio-demographic position correlates polynomially $\left(r^{2}=1\right)$ with socio-demographic success within each socio-demographic order of a given sociodemographic hierarchy (See figure 7).

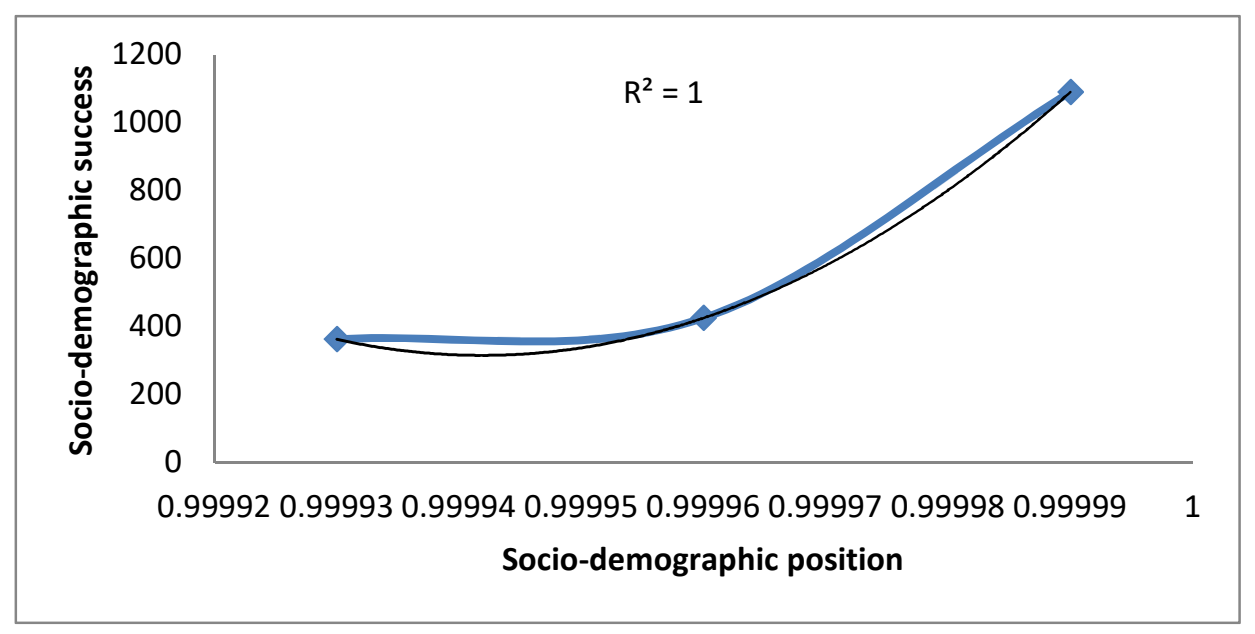

Figure 11: Showing the correlation between socio-demographic position and success. 
SOCIO-DEMOGRAPHIC STATUS

\section{Application of socio-demography of status}

Population census. Socio-demographic status of individuals in a population can be a helpful guide for sorting and estimation the frequency of population individuals with particular or specified demographic or sociological characteristics. It can also be used to show the distribution of people with respect to a certain demographic or sociological attributes.

Candidates screening. Socio-demographic status of applicants can be a simplified approach of sorting individuals with a set of specified demographic and/or sociological attributes of organizational interest. This method could save time scanning and sorting of individuals that have acquired or attain a defined and desired demographic and sociological characteristics.

Medical investigations. Socio-demographic status clients or patients can be an immense important in medical research and investigations. Relationship between a disease and patients' demographic and/or sociological states can be interrelated and correlated to find if any statistically significant effects.

Socio-demographic stratification. Socio-demographic hierarchy can be a more advance approach over the social hierarchy developed by Karl Marx, (1959) and Max Weber (1921/2015) which were based on only one or two social attribute: power, prestige, productivity or materialism.

Personnel evaluation and promotions. Socio-demographic position and success of employee can be a helpful guide for their evaluation and promotion based on the assessed criteria established by the organization.

Profile simplifications. Socio-demographic status of individuals can be summarized characteristics (profile) of his demographic and sociological attainments and achievements. Socio-demographic configuration and score of an individual present his a secured figure or codes describing his demographic and social identity.

Organizational ranking. Socio-demographic status can be use to measure the organizational impacts and its personnel's' potentialities and strength. This can help as a factor in an organizational ranking such as institutional rankings or professional bodies.

Measure of socio-demographic development. Socio-demographic configurations and scores of individuals in a given geographical location, ethnicity, country, etc can be an index of sociodemographic development. 
SOCIO-DEMOGRAPHIC STATUS

\section{Conclusion}

This paper identified socio-demographic position and socio-demographic success as the principal determinant of socio-demographic status of an individual(s) as a as common, universal and desirable positions, achievements, and advantages every individual strives and competes to attain, achieve and maintain which are determined by biological and social environments, driven and regulated by a continuum of competitions (through genetic competition, physiological competition, demographic competition, psychosocial competition) and selectively evolved through the mechanism of genetic selection, physiological selection, demographic selection, psychosocial selection and resultant psychosocial fitness and socio-demographic evolution. The paper presented a new dimension of methodology, quantification, numerical analysis and assessment of an individuals' socio-demographic status and the established hierarchical transitions.

\section{Recommendations}

Empirical studies in the following aspect would provide a better understanding of the sociodemographic description of a population and may permit further decisions, policies and actions.
a) Relationship between socio-demographic status and values.
b) Relationship between socio-demographic status and personalities.
c) Relationship between socio-demographic status and physical/mental diseases.
d) Relationship between socio-demographic status and geographical locations.
e) Relationship between socio-demographic status and ethnicities.
f) Relationship between socio-demographic status and races.
g) Relationship between socio-demographic status and religiosity.
h) Relationship between socio-demographic status and power/prestige.
i) Relationship between socio-demographic status and dominance.
j) Relationship between socio-demographic status and materialism.
k) Relationship between socio-demographic status and criminalities.
1) Relationship between socio-demographic status and mortality rate.
m) Relationship between socio-demographic status and healthy lifestyle.
n) Relationship between socio-demographic status and unhealthy lifestyle. 
SOCIO-DEMOGRAPHIC STATUS

\section{Appendix I}

Table: Showing the socio-demographic hierarchies within the third socio-demographic clade of feminine socio-demographic kingdom

\begin{tabular}{|c|c|c|c|c|c|c|c|}
\hline (SDP) Ranking & (SDS) Ranking & SDc & SDs & SD-Group & SD-Class & SD-Order & SD-Grade \\
\hline $1,9,9,9,9,9$ & $1,3,3,3,3,3$ & 0.99999 & 1090 & Upper & Class 1 & Order 1 & Grade 1 \\
\hline $1,9,9,9,9,6$ & $1,3,3,3,3,2$ & 0.99996 & 425 & “ & “ & “ & Grade 2 \\
\hline $1,9,9,9,9,3$ & $1,3,3,3,3,1$ & 0.99993 & 362 & “" & “" & “" & Grade 3 \\
\hline $1,9,9,9,9,0$ & $1,3,3,3,3,0$ & 0.99990 & 361 & “" & “ & “ & Grade 4 \\
\hline $1,9,9,9,6,9$ & $1,3,3,3,2,3$ & 0.99969 & 879 & “" & Class 1 & Order 2 & Grade 1 \\
\hline $1,9,9,9,6,6$ & $1,3,3,3,2,2$ & 0.99966 & 214 & “" & “" & “" & Grade 2 \\
\hline $1,9,9,9,6,3$ & $1,3,3,3,2,1$ & 0.99963 & 151 & “" & “" & “" & Grade 3 \\
\hline $1,9,9,9,6,0$ & $1,3,3,3,2,0$ & 0.99960 & 150 & “" & “ & “ & Grade 4 \\
\hline $1,9,9,9,3,9$ & $1,3,3,3,1,3$ & 0.99939 & 848 & “" & Class 1 & Order 3 & Grade 1 \\
\hline $1,9,9,9,3,6$ & $1,3,3,3,1,2$ & 0.99936 & 183 & “" & “" & “" & Grade 2 \\
\hline $1,9,9,9,3,3$ & $1,3,3,3,1,1$ & 0.99933 & 120 & “" & “" & “" & Grade 3 \\
\hline $1,9,9,9,3,0$ & $1,3,3,3,1,0$ & 0.99930 & 119 & “" & “" & “" & Grade 4 \\
\hline $1,9,9,9,0,9$ & $1,3,3,3,0,3$ & 0.99909 & 847 & “" & Class 1 & Order 4 & Grade 1 \\
\hline $1,9,9,9,0,6$ & $1,3,3,3,0,2$ & 0.99906 & 182 & “" & “ & “" & Grade 2 \\
\hline $1,9,9,9,0,3$ & $1,3,3,3,0,1$ & 0.99903 & 119 & “" & “" & “" & Grade 3 \\
\hline $1,9,9,9,0,0$ & $1,3,3,3,0,0$ & 0.99900 & 118 & “" & “" & “" & Grade 4 \\
\hline $1,9,9,6,9,9$ & $1,3,3,2,3,3$ & 0.99699 & 1025 & Upper & Class 2 & Order 1 & Grade 1 \\
\hline $1,9,9,6,9,6$ & $1,3,3,2,3,2$ & 0.99696 & 360 & “" & “" & “" & Grade 2 \\
\hline $1,9,9,6,9,3$ & $1,3,3,2,3,1$ & 0.99693 & 297 & “" & “" & “" & Grade 3 \\
\hline $1,9,9,6,9,0$ & $1,3,3,2,3,0$ & 0.99690 & 296 & “" & “" & “" & Grade 4 \\
\hline $1,9,9,6,6,9$ & $1,3,3,2,2,3$ & 0.99669 & 814 & “" & Class 2 & Order 2 & Grade 1 \\
\hline $1,9,9,6,6,6$ & $1,3,3,2,2,2$ & 0.99666 & 149 & 66 & "6 & " & Grade 2 \\
\hline $1,9,9,6,6,3$ & $1,3,3,2,2,1$ & 0.99663 & 86 & “" & “ & “ & Grade 3 \\
\hline $1,9,9,6,6,0$ & $1,3,3,2,2,0$ & 0.99660 & 85 & “" & “" & “" & Grade 4 \\
\hline $1,9,9,6,3,9$ & $1,3,3,2,1,3$ & 0.99639 & 783 & “" & Class 2 & Order 3 & Grade 1 \\
\hline $1,9,9,6,3,6$ & $1,3,3,2,1,2$ & 0.99636 & 118 & 6 & 6 & 6 & Grade 2 \\
\hline $1,9,9,6,3,3$ & $1,3,3,2,1,1$ & 0.99633 & 55 & “" & “" & “" & Grade 3 \\
\hline $1,9,9,6,3,0$ & $1,3,3,2,1,0$ & 0.99630 & 54 & “" & “" & " & Grade 4 \\
\hline $1,9,9,6,0,9$ & $1,3,3,2,0,3$ & 0.99609 & 782 & “" & Class 2 & Order 4 & Grade 1 \\
\hline $1,9,9,6,0,6$ & $1,3,3,2,0,2$ & 0.99606 & 117 & “" & “" & “" & Grade 2 \\
\hline $1,9,9,6,0,3$ & $1,3,3,2,0,1$ & 0.99603 & 54 & “" & “" & “" & Grade 3 \\
\hline $1,9,9,6,0,0$ & $1,3,3,2,0,0$ & 0.99600 & 53 & “" & " & 66 & Grade 4 \\
\hline $1,9,9,3,9,9$ & $1,3,3,1,3,3$ & 0.99399 & 1010 & Upper & Class 3 & Order 1 & Grade 1 \\
\hline $1,9,9,3,9,6$ & $1,3,3,1,3,2$ & 0.99396 & 345 & “" & “" & “" & Grade 2 \\
\hline $1,9,9,3,9,3$ & $1,3,3,1,3,1$ & 0.99393 & 282 & “" & “" & “" & Grade 3 \\
\hline $1,9,9,3,9,0$ & $1,3,3,1,3,0$ & 0.99390 & 281 & “" & “" & “" & Grade 4 \\
\hline
\end{tabular}


SOCIO-DEMOGRAPHIC STATUS

\begin{tabular}{|c|c|c|c|c|c|c|c|}
\hline $1,9,9,3,6,9$ & $1,3,3,1,2,3$ & 0.99369 & 799 & “" & Class 3 & Order 2 & Grade 1 \\
\hline $1,9,9,3,6,6$ & $1,3,3,1,2,2$ & 0.99366 & 134 & “" & “" & “" & Grade 2 \\
\hline $1,9,9,3,6,3$ & $1,3,3,1,2,1$ & 0.99363 & 71 & “" & “" & “" & Grade 3 \\
\hline $1,9,9,3,6,0$ & $1,3,3,1,2,0$ & 0.99360 & 70 & “" & “" & “" & Grade 4 \\
\hline $1,9,9,3,3,9$ & $1,3,3,1,1,3$ & 0.99339 & 768 & “" & Class 3 & Order 3 & Grade 1 \\
\hline $1,9,9,3,3,6$ & $1,3,3,1,1,2$ & 0.99336 & 103 & “" & “" & "“ & Grade 2 \\
\hline $1,9,9,3,3,3$ & $1,3,3,1,1,1$ & 0.99333 & 40 & “" & “" & “" & Grade 3 \\
\hline $1,9,9,3,3,0$ & $1,3,3,1,1,0$ & 0.99330 & 39 & “" & “" & “" & Grade 4 \\
\hline $1,9,9,3,0,9$ & $1,3,3,1,0,3$ & 0.99309 & 767 & “" & Class 3 & Order 4 & Grade 1 \\
\hline $1,9,9,3,0,6$ & $1,3,3,1,0,2$ & 0.99306 & 102 & “" & “" & "“ & Grade 2 \\
\hline $1,9,9,3,0,3$ & $1,3,3,1,0,1$ & 0.99303 & 39 & “" & “6 & “6 & Grade 3 \\
\hline $1,9,9,3,0,0$ & $1,3,3,1,0,0$ & 0.99300 & 38 & “" & “" & “" & Grade 4 \\
\hline $1,9,9,0,9,9$ & $1,3,3,0,3,3$ & 0.99099 & 1009 & Upper & Class 4 & Order 1 & Grade 1 \\
\hline $1,9,9,0,9,6$ & $1,3,3,0,3,2$ & 0.99096 & 344 & "“ & “" & "“ & Grade 2 \\
\hline $1,9,9,0,9,3$ & $1,3,3,0,3,1$ & 0.99093 & 281 & “" & “" & “" & Grade 3 \\
\hline $1,9,9,0,9,0$ & $1,3,3,0,3,0$ & 0.99090 & 280 & “" & “" & “" & Grade 4 \\
\hline $1,9,9,0,6,9$ & $1,3,3,0,2,3$ & 0.99069 & 798 & “" & Class 4 & Order 2 & Grade 1 \\
\hline $1,9,9,0,6,6$ & $1,3,3,0,2,2$ & 0.99066 & 133 & “" & “" & “" & Grade 2 \\
\hline $1,9,9,0,6,3$ & $1,3,3,0,2,1$ & 0.99063 & 70 & “" & “" & “" & Grade 3 \\
\hline $1,9,9,0,6,0$ & $1,3,3,0,2,0$ & 0.99060 & 69 & “" & “" & “" & Grade 4 \\
\hline $1,9,9,0,3,9$ & $1,3,3,0,1,3$ & 0.99039 & 767 & “" & Class 4 & Order 3 & Grade 1 \\
\hline $1,9,9,0,3,6$ & $1,3,3,0,1,2$ & 0.99036 & 102 & "“ & “" & “" & Grade 2 \\
\hline $1,9,9,0,3,3$ & $1,3,3,0,1,1$ & 0.99033 & 39 & “" & “" & “" & Grade 3 \\
\hline $1,9,9,0,3,0$ & $1,3,3,0,1,0$ & 0.99030 & 38 & “" & “" & “" & Grade 4 \\
\hline $1,9,9,0,0,9$ & $1,3,3,0,0,3$ & 0.99009 & 766 & “" & Class 4 & Order 4 & Grade 1 \\
\hline $1,9,9,0,0,6$ & $1,3,3,0,0,2$ & 0.99006 & 101 & “" & “" & “" & Grade 2 \\
\hline $1,9,9,0,0,3$ & $1,3,3,0,0,1$ & 0.99003 & 38 & “" & “" & “" & Grade 3 \\
\hline $1,9,9,0,0,0$ & $1,3,3,0,0,0$ & 0.99000 & 37 & “" & “" & “" & Grade 4 \\
\hline $1,9,6,9,9,9$ & $1,3,2,3,3,3$ & 0.96999 & 1071 & Middle & Class 1 & Order 1 & Grade 1 \\
\hline $1,9,6,9,9,6$ & $1,3,2,3,3,2$ & 0.96996 & 406 & “" & “" & “6 & Grade 2 \\
\hline $1,9,6,9,9,3$ & $1,3,2,3,3,1$ & 0.96993 & 343 & “" & “" & “" & Grade 3 \\
\hline $1,9,6,9,9,0$ & $1,3,2,3,3,0$ & 0.96990 & 342 & “" & “" & “" & Grade 4 \\
\hline $1,9,6,9,6,9$ & $1,3,2,3,2,3$ & 0.96969 & 860 & “" & Class 1 & Order 2 & Grade 1 \\
\hline $1,9,6,9,6,6$ & $1,3,2,3,2,2$ & 0.96966 & 195 & “" & "“ & "“ & Grade 2 \\
\hline $1,9,6,9,6,3$ & $1,3,2,3,2,1$ & 0.96963 & 132 & “" & “" & 66 & Grade 3 \\
\hline $1,9,6,9,6,0$ & $1,3,2,3,2,0$ & 0.96960 & 131 & “" & “" & “" & Grade 4 \\
\hline $1,9,6,9,3,9$ & $1,3,2,3,1,3$ & 0.96939 & 829 & “" & Class 1 & Order 3 & Grade 1 \\
\hline $1,9,6,9,3,6$ & $1,3,2,3,1,2$ & 0.96936 & 164 & “" & “" & “" & Grade 2 \\
\hline $1,9,6,9,3,3$ & $1,3,2,3,1,1$ & 0.96933 & 101 & “" & “" & "“ & Grade 3 \\
\hline $1,9,6,9,3,0$ & $1,3,2,3,1,0$ & 0.96930 & 100 & “" & “" & “" & Grade 4 \\
\hline $1,9,6,9,0,9$ & $1,3,2,3,0,3$ & 0.96909 & 828 & “" & Class 1 & Order 4 & Grade 1 \\
\hline $1,9,6,9,0,6$ & $1,3,2,3,0,2$ & 0.96906 & 163 & “" & “ & “" & Grade 2 \\
\hline
\end{tabular}


SOCIO-DEMOGRAPHIC STATUS

\begin{tabular}{|c|c|c|c|c|c|c|c|}
\hline $1,9,6,9,0,3$ & $1,3,2,3,0,1$ & 0.96903 & 100 & “" & “" & “" & Grade 3 \\
\hline $1,9,6,9,0,0$ & $1,3,2,3,0,0$ & 0.96900 & 99 & “" & “" & “" & Grade 4 \\
\hline $1,9,6,6,9,9$ & $1,3,2,2,3,3$ & 0.96699 & 1006 & Middle & Class 2 & Order 1 & Grade 1 \\
\hline $1,9,6,6,9,6$ & $1,3,2,2,3,2$ & 0.96696 & 341 & “" & “" & “" & Grade 2 \\
\hline $1,9,6,6,9,3$ & $1,3,2,2,3,1$ & 0.96693 & 278 & “" & “" & “" & Grade 3 \\
\hline $1,9,6,6,9,0$ & $1,3,2,2,3,0$ & 0.96690 & 277 & “" & “" & “" & Grade 4 \\
\hline $1,9,6,6,6,9$ & $1,3,2,2,2,3$ & 0.96669 & 795 & "“ & Class 2 & Order 2 & Grade 1 \\
\hline $1,9,6,6,6,6$ & $1,3,2,2,2,2$ & 0.96666 & 130 & “" & “" & “" & Grade 2 \\
\hline $1,9,6,6,6,3$ & $1,3,2,2,2,1$ & 0.96663 & 67 & “" & “" & “" & Grade 3 \\
\hline $1,9,6,6,6,0$ & $1,3,2,2,2,0$ & 0.96660 & 66 & “" & “" & “" & Grade 4 \\
\hline $1,9,6,6,3,9$ & $1,3,2,2,1,3$ & 0.96639 & 764 & “" & Class 2 & Order 3 & Grade 1 \\
\hline $1,9,6,6,3,6$ & $1,3,2,2,1,2$ & 0.96636 & 99 & “" & “" & “" & Grade 2 \\
\hline $1,9,6,6,3,3$ & $1,3,2,2,1,1$ & 0.96633 & 36 & “" & “" & “" & Grade 3 \\
\hline $1,9,6,6,3,0$ & $1,3,2,2,1,0$ & 0.96630 & 35 & “" & “" & “" & Grade 4 \\
\hline $1,9,6,6,0,9$ & $1,3,2,2,0,3$ & 0.96609 & 763 & “" & Class 2 & Order 4 & Grade 1 \\
\hline $1,9,6,6,0,6$ & $1,3,2,2,0,2$ & 0.96606 & 98 & “" & “" & “" & Grade 2 \\
\hline $1,9,6,6,0,3$ & $1,3,2,2,0,1$ & 0.96603 & 35 & “" & “" & “" & Grade 3 \\
\hline $1,9,6,6,0,0$ & $1,3,2,2,0,0$ & 0.96600 & 34 & “" & “" & “" & Grade 4 \\
\hline $1,9,6,3,9,9$ & $1,3,2,1,3,3$ & 0.96399 & 991 & Middle & Class 3 & Order 1 & Grade 1 \\
\hline $1,9,6,3,9,6$ & $1,3,2,1,3,2$ & 0.96396 & 326 & “" & “" & “" & Grade 2 \\
\hline $1,9,6,3,9,3$ & $1,3,2,1,3,1$ & 0.96393 & 263 & “" & “" & “" & Grade 3 \\
\hline $1,9,6,3,9,0$ & $1,3,2,1,3,0$ & 0.96390 & 262 & "“ & “" & “" & Grade 4 \\
\hline $1,9,6,3,6,9$ & $1,3,2,1,2,3$ & 0.96369 & 780 & “6 & Class 3 & Order 2 & Grade 1 \\
\hline $1,9,6,3,6,6$ & $1,3,2,1,2,2$ & 0.96366 & 115 & “" & “" & “" & Grade 2 \\
\hline $1,9,6,3,6,3$ & $1,3,2,1,2,1$ & 0.96363 & 52 & “" & “" & “" & Grade 3 \\
\hline $1,9,6,3,6,0$ & $1,3,2,1,2,0$ & 0.96360 & 51 & “" & “" & “" & Grade 4 \\
\hline $1,9,6,3,3,9$ & $1,3,2,1,1,3$ & 0.96339 & 749 & “" & Class 3 & Order 3 & Grade 1 \\
\hline $1,9,6,3,3,6$ & $1,3,2,1,1,2$ & 0.96336 & 84 & “" & “" & “" & Grade 2 \\
\hline $1,9,6,3,3,3$ & $1,3,2,1,1,1$ & 0.96333 & 21 & “" & “" & "“ & Grade 3 \\
\hline $1,9,6,3,3,0$ & $1,3,2,1,1,0$ & 0.96330 & 20 & “" & “" & “" & Grade 4 \\
\hline $1,9,6,3,0,9$ & $1,3,2,1,0,3$ & 0.96309 & 748 & “" & Class 3 & Order 4 & Grade 1 \\
\hline $1,9,6,3,0,6$ & $1,3,2,1,0,2$ & 0.96306 & 83 & “" & “" & “" & Grade 2 \\
\hline $1,9,6,3,0,3$ & $1,3,2,1,0,1$ & 0.96303 & 20 & “ & "“ & "6 & Grade 3 \\
\hline $1,9,6,3,0,0$ & $1,3,2,1,0,0$ & 0.96300 & 19 & “" & “ & “ & Grade 4 \\
\hline $1,9,6,0,9,9$ & $1,3,2,0,3,3$ & 0.96099 & 990 & Middle & Class 4 & Order 1 & Grade 1 \\
\hline $1,9,6,0,9,6$ & $1,3,2,0,3,2$ & 0.96096 & 325 & “" & “" & “" & Grade 2 \\
\hline $1,9,6,0,9,3$ & $1,3,2,0,3,1$ & 0.96093 & 262 & “" & “" & “" & Grade 3 \\
\hline $1,9,6,0,9,0$ & $1,3,2,0,3,0$ & 0.96090 & 261 & “" & “" & “" & Grade 4 \\
\hline $1,9,6,0,6,9$ & $1,3,2,0,2,3$ & 0.96069 & 779 & “" & Class 4 & Order 2 & Grade 1 \\
\hline $1,9,6,0,6,6$ & $1,3,2,0,2,2$ & 0.96066 & 114 & “" & “" & “" & Grade 2 \\
\hline $1,9,6,0,6,3$ & $1,3,2,0,2,1$ & 0.96063 & 51 & “ & “ & “ & Grade 3 \\
\hline $1,9,6,0,6,0$ & $1,3,2,0,2,0$ & 0.96060 & 50 & “" & “ & “ & Grade 4 \\
\hline
\end{tabular}


SOCIO-DEMOGRAPHIC STATUS

\begin{tabular}{|c|c|c|c|c|c|c|c|}
\hline $1,9,6,0,3,9$ & $1,3,2,0,1,3$ & 0.96039 & 748 & “" & Class 4 & Order 3 & Grade 1 \\
\hline $1,9,6,0,3,6$ & $1,3,2,0,1,2$ & 0.96036 & 83 & “" & “" & “" & Grade 2 \\
\hline $1,9,6,0,3,3$ & $1,3,2,0,1,1$ & 0.96033 & 20 & “" & “" & “" & Grade 3 \\
\hline $1,9,6,0,3,0$ & $1,3,2,0,1,0$ & 0.96030 & 19 & “" & “" & "، & Grade 4 \\
\hline $1,9,6,0,0,9$ & $1,3,2,0,0,3$ & 0.96009 & 747 & “" & Class 4 & Order 4 & Grade 1 \\
\hline $1,9,6,0,0,6$ & $1,3,2,0,0,2$ & 0.96006 & 82 & “" & “" & “" & Grade 2 \\
\hline $1,9,6,0,0,3$ & $1,3,2,0,0,1$ & 0.96003 & 19 & "“ & “" & “" & Grade 3 \\
\hline $1,9,6,0,0,0$ & $1,3,2,0,0,0$ & 0.96000 & 18 & “" & “" & “" & Grade 4 \\
\hline $1,9,3,9,9,9$ & $1,3,1,3,3,3$ & 0.96999 & 1064 & Lower & Class 1 & Order 1 & Grade 1 \\
\hline $1,9,3,9,9,6$ & $1,3,1,3,3,2$ & 0.96996 & 399 & “" & “" & “" & Grade 2 \\
\hline $1,9,3,9,9,3$ & $1,3,1,3,3,1$ & 0.96993 & 336 & “" & “" & “6 & Grade 3 \\
\hline $1,9,3,9,9,0$ & $1,3,1,3,3,0$ & 0.96990 & 335 & “" & “" & “" & Grade 4 \\
\hline $1,9,3,9,6,9$ & $1,3,1,3,2,3$ & 0.96969 & 853 & “" & Class 1 & Order 2 & Grade 1 \\
\hline $1,9,3,9,6,6$ & $1,3,1,3,2,2$ & 0.96966 & 188 & “" & “" & “" & Grade 2 \\
\hline $1,9,3,9,6,3$ & $1,3,1,3,2,1$ & 0.96963 & 125 & “" & " & 6 & Grade 3 \\
\hline $1,9,3,9,6,0$ & $1,3,1,3,2,0$ & 0.96960 & 124 & “" & “" & “" & Grade 4 \\
\hline $1,9,3,9,3,9$ & $1,3,1,3,1,3$ & 0.96939 & 822 & “" & Class 1 & Order 3 & Grade 1 \\
\hline $1,9,3,9,3,6$ & $1,3,1,3,1,2$ & 0.96936 & 157 & “" & “" & “" & Grade 2 \\
\hline $1,9,3,9,3,3$ & $1,3,1,3,1,1$ & 0.96933 & 94 & “" & "“ & "، & Grade 3 \\
\hline $1,9,3,9,3,0$ & $1,3,1,3,1,0$ & 0.96930 & 93 & “" & “" & “" & Grade 4 \\
\hline $1,9,3,9,0,9$ & $1,3,1,3,0,3$ & 0.96909 & 821 & “" & Class 1 & Order 4 & Grade 1 \\
\hline $1,9,3,9,0,6$ & $1,3,1,3,0,2$ & 0.96906 & 156 & "“ & “" & “" & Grade 2 \\
\hline $1,9,3,9,0,3$ & $1,3,1,3,0,1$ & 0.96903 & 93 & “" & “" & 6 & Grade 3 \\
\hline $1,9,3,9,0,0$ & $1,3,1,3,0,0$ & 0.96900 & 92 & “" & “" & “" & Grade 4 \\
\hline $1,9,3,6,9,9$ & $1,3,1,2,3,3$ & 0.96699 & 999 & Lower & Class 2 & Order 1 & Grade 1 \\
\hline $1,9,3,6,9,6$ & $1,3,1,2,3,2$ & 0.96696 & 334 & “" & “" & “" & Grade 2 \\
\hline $1,9,3,6,9,3$ & $1,3,1,2,3,1$ & 0.96693 & 271 & “" & “" & “" & Grade 3 \\
\hline $1,9,3,6,9,0$ & $1,3,1,2,3,0$ & 0.96690 & 270 & “" & “" & “" & Grade 4 \\
\hline $1,9,3,6,6,9$ & $1,3,1,2,2,3$ & 0.96669 & 788 & “" & Class 2 & Order 2 & Grade 1 \\
\hline $1,9,3,6,6,6$ & $1,3,1,2,2,2$ & 0.96666 & 123 & “ & “" & “" & Grade 2 \\
\hline $1,9,3,6,6,3$ & $1,3,1,2,2,1$ & 0.96663 & 60 & “" & “" & “" & Grade 3 \\
\hline $1,9,3,6,6,0$ & $1,3,1,2,2,0$ & 0.96660 & 59 & “" & “" & “" & Grade 4 \\
\hline $1,9,3,6,3,9$ & $1,3,1,2,1,3$ & 0.96639 & 757 & “" & Class 2 & Order 3 & Grade 1 \\
\hline $1,9,3,6,3,6$ & $1,3,1,2,1,2$ & 0.96636 & 92 & “" & “" & “" & Grade 2 \\
\hline $1,9,3,6,3,3$ & $1,3,1,2,1,1$ & 0.96633 & 29 & “" & "6 & 6 & Grade 3 \\
\hline $1,9,3,6,3,0$ & $1,3,1,2,1,0$ & 0.96630 & 28 & “" & “" & ") & Grade 4 \\
\hline $1,9,3,6,0,9$ & $1,3,1,2,0,3$ & 0.96609 & 756 & “" & Class 2 & Order 4 & Grade 1 \\
\hline $1,9,3,6,0,6$ & $1,3,1,2,0,2$ & 0.96606 & 91 & “" & “" & “" & Grade 2 \\
\hline $1,9,3,6,0,3$ & $1,3,1,2,0,1$ & 0.96603 & 28 & “" & “" & "“ & Grade 3 \\
\hline $1,9,3,6,0,0$ & $1,3,1,2,0,0$ & 0.96600 & 27 & “" & “" & “" & Grade 4 \\
\hline $1,9,3,3,9,9$ & $1,3,1,1,3,3$ & 0.96399 & 984 & Lower & Class 3 & Order 1 & Grade 1 \\
\hline $1,9,3,3,9,6$ & $1,3,1,1,3,2$ & 0.96396 & 319 & “" & “ & “ & Grade 2 \\
\hline
\end{tabular}


SOCIO-DEMOGRAPHIC STATUS

\begin{tabular}{|c|c|c|c|c|c|c|c|}
\hline $1,9,3,3,9,3$ & $1,3,1,1,3,1$ & 0.96393 & 256 & “" & “" & “" & Grade 3 \\
\hline $1,9,3,3,9,0$ & $1,3,1,1,3,0$ & 0.96390 & 255 & “" & "“ & "6 & Grade 4 \\
\hline $1,9,3,3,6,9$ & $1,3,1,1,2,3$ & 0.96369 & 773 & “" & Class 3 & Order 2 & Grade 1 \\
\hline $1,9,3,3,6,6$ & $1,3,1,1,2,2$ & 0.96366 & 108 & “" & “" & "6 & Grade 2 \\
\hline $1,9,3,3,6,3$ & $1,3,1,1,2,1$ & 0.96363 & 45 & “" & “" & “" & Grade 3 \\
\hline $1,9,3,3,6,0$ & $1,3,1,1,2,0$ & 0.96360 & 44 & “" & “" & “" & Grade 4 \\
\hline $1,9,3,3,3,9$ & $1,3,1,1,1,3$ & 0.96339 & 742 & “" & Class 3 & Order 3 & Grade 1 \\
\hline $1,9,3,3,3,6$ & $1,3,1,1,1,2$ & 0.96336 & 77 & “" & "“ & ") & Grade 2 \\
\hline $1,9,3,3,3,3$ & $1,3,1,1,1,1$ & 0.96333 & 14 & “" & “" & “" & Grade 3 \\
\hline $1,9,3,3,3,0$ & $1,3,1,1,1,0$ & 0.96330 & 13 & “" & “" & “" & Grade 4 \\
\hline $1,9,3,3,0,9$ & $1,3,1,1,0,3$ & 0.96309 & 741 & “ & Class 3 & Order 4 & Grade 1 \\
\hline $1,9,3,3,0,6$ & $1,3,1,1,0,2$ & 0.96306 & 76 & “" & "“ & "“ & Grade 2 \\
\hline $1,9,3,3,0,3$ & $1,3,1,1,0,1$ & 0.96303 & 13 & “" & “" & “" & Grade 3 \\
\hline $1,9,3,3,0,0$ & $1,3,1,1,0,0$ & 0.96300 & 12 & “" & “" & “" & Grade 4 \\
\hline $1,9,3,0,9,9$ & $1,3,1,0,3,3$ & 0.96099 & 983 & Lower & Class 4 & Order 1 & Grade 1 \\
\hline $1,9,3,0,9,6$ & $1,3,1,0,3,2$ & 0.96096 & 318 & “" & 66 & "6 & Grade 2 \\
\hline $1,9,3,0,9,3$ & $1,3,1,0,3,1$ & 0.96093 & 255 & “" & "6 & "6 & Grade 3 \\
\hline $1,9,3,0,9,0$ & $1,3,1,0,3,0$ & 0.96090 & 254 & “" & “ & “ & Grade 4 \\
\hline $1,9,3,0,6,9$ & $1,3,1,0,2,3$ & 0.96069 & 772 & “" & Class 4 & Order 2 & Grade 1 \\
\hline $1,9,3,0,6,6$ & $1,3,1,0,2,2$ & 0.96066 & 107 & “" & “" & “" & Grade 2 \\
\hline $1,9,3,0,6,3$ & $1,3,1,0,2,1$ & 0.96063 & 44 & “" & “" & “" & Grade 3 \\
\hline $1,9,3,0,6,0$ & $1,3,1,0,2,0$ & 0.96060 & 43 & “" & “ & “ & Grade 4 \\
\hline $1,9,3,0,3,9$ & $1,3,1,0,1,3$ & 0.96039 & 741 & “" & Class 4 & Order 3 & Grade 1 \\
\hline $1,9,3,0,3,6$ & $1,3,1,0,1,2$ & 0.96036 & 76 & “" & “" & "“ & Grade 2 \\
\hline $1,9,3,0,3,3$ & $1,3,1,0,1,1$ & 0.96033 & 13 & “" & “" & “" & Grade 3 \\
\hline $1,9,3,0,3,0$ & $1,3,1,0,1,0$ & 0.96030 & 12 & “" & “ & “ & Grade 4 \\
\hline $1,9,3,0,0,9$ & $1,3,1,0,0,3$ & 0.96009 & 740 & “" & Class 4 & Order 4 & Grade 1 \\
\hline $1,9,3,0,0,6$ & $1,3,1,0,0,2$ & 0.96006 & 75 & “" & "“ & ، & Grade 2 \\
\hline $1,9,3,0,0,3$ & $1,3,1,0,0,1$ & 0.96003 & 12 & “" & “" & “" & Grade 3 \\
\hline $1,9,3,0,0,0$ & $1,3,1,0,0,0$ & 0.96000 & 11 & “" & “" & “" & Grade 4 \\
\hline
\end{tabular}


SOCIO-DEMOGRAPHIC STATUS

\section{Appendix II}

Table: Showing the socio-demographic hierarchies within the second socio-demographic clade of feminine socio-demographic kingdom

\begin{tabular}{|c|c|c|c|c|c|c|c|}
\hline (SDP) Ranking & (SDS) Ranking & SDc & SDs & SD-Group & SD-Class & SD-Order & SD-Grade \\
\hline $1,6,9,9,9,9$ & $1,2,3,3,3,3$ & 0.69999 & 1085 & Upper & Class 1 & Order 1 & Grade 1 \\
\hline $1,6,9,9,9,6$ & $1,2,3,3,3,2$ & 0.69996 & 420 & “" & “" & “" & Grade 2 \\
\hline $1,6,9,9,9,3$ & $1,2,3,3,3,1$ & 0.69993 & 357 & “" & “" & 6" & Grade 3 \\
\hline $1,6,9,9,9,0$ & $1,2,3,3,3,0$ & 0.69990 & 356 & “" & “6 & “" & Grade 4 \\
\hline $1,6,9,9,6,9$ & $1,2,3,3,2,3$ & 0.69969 & 874 & “" & Class 1 & Order 2 & Grade 1 \\
\hline $1,6,9,9,6,6$ & $1,2,3,3,2,2$ & 0.69966 & 209 & “" & “" & “" & Grade 2 \\
\hline $1,6,9,9,6,3$ & $1,2,3,3,2,1$ & 0.69963 & 146 & "“ & " & "“ & Grade 3 \\
\hline $1,6,9,9,6,0$ & $1,2,3,3,2,0$ & 0.69960 & 145 & “" & “" & “" & Grade 4 \\
\hline $1,6,9,9,3,9$ & $1,2,3,3,1,3$ & 0.69939 & 843 & “" & Class 1 & Order 3 & Grade 1 \\
\hline $1,6,9,9,3,6$ & $1,2,3,3,1,2$ & 0.69936 & 178 & “" & “" & "“ & Grade 2 \\
\hline $1,6,9,9,3,3$ & $1,2,3,3,1,1$ & 0.69933 & 115 & “" & “" & “" & Grade 3 \\
\hline $1,6,9,9,3,0$ & $1,2,3,3,1,0$ & 0.69930 & 114 & “" & “ & “" & Grade 4 \\
\hline $1,6,9,9,0,9$ & $1,2,3,3,0,3$ & 0.69909 & 842 & “" & Class 1 & Order 4 & Grade 1 \\
\hline $1,6,9,9,0,6$ & $1,2,3,3,0,2$ & 0.69906 & 177 & “" & “" & "“ & Grade 2 \\
\hline $1,6,9,9,0,3$ & $1,2,3,3,0,1$ & 0.69903 & 114 & “ & “ & “" & Grade 3 \\
\hline $1,6,9,9,0,0$ & $1,2,3,3,0,0$ & 0.69900 & 113 & “" & “" & “" & Grade 4 \\
\hline $1,6,9,6,9,9$ & $1,2,3,2,3,3$ & 0.69699 & 1020 & Upper & Class 2 & Order 1 & Grade 1 \\
\hline $1,6,9,6,9,6$ & $1,2,3,2,3,2$ & 0.69696 & 355 & “" & “" & "“ & Grade 2 \\
\hline $1,6,9,6,9,3$ & $1,2,3,2,3,1$ & 0.69693 & 292 & “" & “" & " & Grade 3 \\
\hline $1,6,9,6,9,0$ & $1,2,3,2,3,0$ & 0.69690 & 291 & “" & “" & “" & Grade 4 \\
\hline $1,6,9,6,6,9$ & $1,2,3,2,2,3$ & 0.69669 & 809 & “" & Class 2 & Order 2 & Grade 1 \\
\hline $1,6,9,6,6,6$ & $1,2,3,2,2,2$ & 0.69666 & 144 & “" & “" & "“ & Grade 2 \\
\hline $1,6,9,6,6,3$ & $1,2,3,2,2,1$ & 0.69663 & 81 & “" & “" & “" & Grade 3 \\
\hline $1,6,9,6,6,0$ & $1,2,3,2,2,0$ & 0.69660 & 80 & “ & “ & “ & Grade 4 \\
\hline $1,6,9,6,3,9$ & $1,2,3,2,1,3$ & 0.69639 & 778 & “" & Class 2 & Order 3 & Grade 1 \\
\hline $1,6,9,6,3,6$ & $1,2,3,2,1,2$ & 0.69636 & 113 & “" & “" & "“ & Grade 2 \\
\hline $1,6,9,6,3,3$ & $1,2,3,2,1,1$ & 0.69633 & 50 & “" & “" & “" & Grade 3 \\
\hline $1,6,9,6,3,0$ & $1,2,3,2,1,0$ & 0.69630 & 49 & “ & “ & “" & Grade 4 \\
\hline $1,6,9,6,0,9$ & $1,2,3,2,0,3$ & 0.69609 & 777 & “ & Class 2 & Order 4 & Grade 1 \\
\hline $1,6,9,6,0,6$ & $1,2,3,2,0,2$ & 0.69606 & 112 & “" & “" & “" & Grade 2 \\
\hline $1,6,9,6,0,3$ & $1,2,3,2,0,1$ & 0.69603 & 49 & “" & "“ & “" & Grade 3 \\
\hline $1,6,9,6,0,0$ & $1,2,3,2,0,0$ & 0.69600 & 48 & “" & “ & “ & Grade 4 \\
\hline $1,6,9,3,9,9$ & $1,2,3,1,3,3$ & 0.69399 & 1005 & Upper & Class 3 & Order 1 & Grade 1 \\
\hline $1,6,9,3,9,6$ & $1,2,3,1,3,2$ & 0.69396 & 340 & “" & “" & “" & Grade 2 \\
\hline $1,6,9,3,9,3$ & $1,2,3,1,3,1$ & 0.69393 & 277 & “" & “" & “" & Grade 3 \\
\hline $1,6,9,3,9,0$ & $1,2,3,1,3,0$ & 0.69390 & 276 & “" & “" & “" & Grade 4 \\
\hline $1,6,9,3,6,9$ & $1,2,3,1,2,3$ & 0.69369 & 794 & “" & Class 3 & Order 2 & Grade 1 \\
\hline
\end{tabular}


SOCIO-DEMOGRAPHIC STATUS

\begin{tabular}{|c|c|c|c|c|c|c|c|}
\hline $1,6,9,3,6,6$ & $1,2,3,1,2,2$ & 0.69366 & 129 & “" & “" & " & Grade 2 \\
\hline $1,6,9,3,6,3$ & $1,2,3,1,2,1$ & 0.69363 & 66 & “" & “" & “" & Grade 3 \\
\hline $1,6,9,3,6,0$ & $1,2,3,1,2,0$ & 0.69360 & 65 & “" & “" & “" & Grade 4 \\
\hline $1,6,9,3,3,9$ & $1,2,3,1,1,3$ & 0.69339 & 763 & “6 & Class 3 & Order 3 & Grade 1 \\
\hline $1,6,9,3,3,6$ & $1,2,3,1,1,2$ & 0.69336 & 98 & “" & “" & “" & Grade 2 \\
\hline $1,6,9,3,3,3$ & $1,2,3,1,1,1$ & 0.69333 & 35 & “" & “" & “" & Grade 3 \\
\hline $1,6,9,3,3,0$ & $1,2,3,1,1,0$ & 0.69330 & 34 & “" & “" & “" & Grade 4 \\
\hline $1,6,9,3,0,9$ & $1,2,3,1,0,3$ & 0.69309 & 762 & “" & Class 3 & Order 4 & Grade 1 \\
\hline $1,6,9,3,0,6$ & $1,2,3,1,0,2$ & 0.69306 & 97 & “" & “" & “" & Grade 2 \\
\hline $1,6,9,3,0,3$ & $1,2,3,1,0,1$ & 0.69303 & 34 & “" & “" & “" & Grade 3 \\
\hline $1,6,9,3,0,0$ & $1,2,3,1,0,0$ & 0.69300 & 33 & “" & “" & “" & Grade 4 \\
\hline $1,6,9,0,9,9$ & $1,2,3,0,3,3$ & 0.69099 & 1004 & Upper & Class 4 & Order 1 & Grade 1 \\
\hline $1,6,9,0,9,6$ & $1,2,3,0,3,2$ & 0.69096 & 339 & “" & “" & “" & Grade 2 \\
\hline $1,6,9,0,9,3$ & $1,2,3,0,3,1$ & 0.69093 & 276 & “" & “" & “" & Grade 3 \\
\hline $1,6,9,0,9,0$ & $1,2,3,0,3,0$ & 0.69090 & 275 & “" & "6 & 6 & Grade 4 \\
\hline $1,6,9,0,6,9$ & $1,2,3,0,2,3$ & 0.69069 & 793 & “" & Class 4 & Order 2 & Grade 1 \\
\hline $1,6,9,0,6,6$ & $1,2,3,0,2,2$ & 0.69066 & 128 & “" & “" & "“ & Grade 2 \\
\hline $1,6,9,0,6,3$ & $1,2,3,0,2,1$ & 0.69063 & 65 & “" & “" & “" & Grade 3 \\
\hline $1,6,9,0,6,0$ & $1,2,3,0,2,0$ & 0.69060 & 64 & “" & "“ & " & Grade 4 \\
\hline $1,6,9,0,3,9$ & $1,2,3,0,1,3$ & 0.69039 & 762 & “" & Class 4 & Order 3 & Grade 1 \\
\hline $1,6,9,0,3,6$ & $1,2,3,0,1,2$ & 0.69036 & 97 & “" & “" & "“ & Grade 2 \\
\hline $1,6,9,0,3,3$ & $1,2,3,0,1,1$ & 0.69033 & 34 & "“ & “" & “" & Grade 3 \\
\hline $1,6,9,0,3,0$ & $1,2,3,0,1,0$ & 0.69030 & 33 & “" & “" & “" & Grade 4 \\
\hline $1,6,9,0,0,9$ & $1,2,3,0,0,3$ & 0.69009 & 761 & “" & Class 4 & Order 4 & Grade 1 \\
\hline $1,6,9,0,0,6$ & $1,2,3,0,0,2$ & 0.69006 & 96 & “" & “" & “" & Grade 2 \\
\hline $1,6,9,0,0,3$ & $1,2,3,0,0,1$ & 0.69003 & 33 & “" & “" & “" & Grade 3 \\
\hline $1,6,9,0,0,0$ & $1,2,3,0,0,0$ & 0.69000 & 32 & “" & “" & “" & Grade 4 \\
\hline $1,6,6,9,9,9$ & $1,2,2,3,3,3$ & 0.66999 & 1066 & Middle & Class 1 & Order 1 & Grade 1 \\
\hline $1,6,6,9,9,6$ & $1,2,2,3,3,2$ & 0.66996 & 401 & “" & “" & “" & Grade 2 \\
\hline $1,6,6,9,9,3$ & $1,2,2,3,3,1$ & 0.66993 & 338 & “" & “" & “" & Grade 3 \\
\hline $1,6,6,9,9,0$ & $1,2,2,3,3,0$ & 0.66990 & 337 & “" & “" & “" & Grade 4 \\
\hline $1,6,6,9,6,9$ & $1,2,2,3,2,3$ & 0.66969 & 855 & “" & Class 1 & Order 2 & Grade 1 \\
\hline $1,6,6,9,6,6$ & $1,2,2,3,2,2$ & 0.66966 & 190 & “" & “" & “" & Grade 2 \\
\hline $1,6,6,9,6,3$ & $1,2,2,3,2,1$ & 0.66963 & 127 & “" & “" & “" & Grade 3 \\
\hline $1,6,6,9,6,0$ & $1,2,2,3,2,0$ & 0.66960 & 126 & “" & “" & 66 & Grade 4 \\
\hline $1,6,6,9,3,9$ & $1,2,2,3,1,3$ & 0.66939 & 824 & “" & Class 1 & Order 3 & Grade 1 \\
\hline $1,6,6,9,3,6$ & $1,2,2,3,1,2$ & 0.66936 & 159 & “" & “" & “" & Grade 2 \\
\hline $1,6,6,9,3,3$ & $1,2,2,3,1,1$ & 0.66933 & 96 & “" & “" & “" & Grade 3 \\
\hline $1,6,6,9,3,0$ & $1,2,2,3,1,0$ & 0.66930 & 95 & “" & “" & “" & Grade 4 \\
\hline $1,6,6,9,0,9$ & $1,2,2,3,0,3$ & 0.66909 & 823 & “" & Class 1 & Order 4 & Grade 1 \\
\hline $1,6,6,9,0,6$ & $1,2,2,3,0,2$ & 0.66906 & 158 & “" & “" & “" & Grade 2 \\
\hline $1,6,6,9,0,3$ & $1,2,2,3,0,1$ & 0.66903 & 95 & “" & “" & “" & Grade 3 \\
\hline
\end{tabular}


SOCIO-DEMOGRAPHIC STATUS

\begin{tabular}{|c|c|c|c|c|c|c|c|}
\hline $1,6,6,9,0,0$ & $1,2,2,3,0,0$ & 0.66900 & 94 & “" & “" & " & Grade 4 \\
\hline $1,6,6,6,9,9$ & $1,2,2,2,3,3$ & 0.66699 & 1001 & Middle & Class 2 & Order 1 & Grade 1 \\
\hline $1,6,6,6,9,6$ & $1,2,2,2,3,2$ & 0.66696 & 336 & “" & “" & “" & Grade 2 \\
\hline $1,6,6,6,9,3$ & $1,2,2,2,3,1$ & 0.66693 & 273 & “" & “" & “" & Grade 3 \\
\hline $1,6,6,6,9,0$ & $1,2,2,2,3,0$ & 0.66690 & 272 & “" & “" & “" & Grade 4 \\
\hline $1,6,6,6,6,9$ & $1,2,2,2,2,3$ & 0.66669 & 790 & “" & Class 2 & Order 2 & Grade 1 \\
\hline $1,6,6,6,6,6$ & $1,2,2,2,2,2$ & 0.66666 & 125 & "“ & “" & “" & Grade 2 \\
\hline $1,6,6,6,6,3$ & $1,2,2,2,2,1$ & 0.66663 & 62 & “" & “" & “" & Grade 3 \\
\hline $1,6,6,6,6,0$ & $1,2,2,2,2,0$ & 0.66660 & 61 & “" & “" & “" & Grade 4 \\
\hline $1,6,6,6,3,9$ & $1,2,2,2,1,3$ & 0.66639 & 759 & “" & Class 2 & Order 3 & Grade 1 \\
\hline $1,6,6,6,3,6$ & $1,2,2,2,1,2$ & 0.66636 & 94 & “" & “" & “" & Grade 2 \\
\hline $1,6,6,6,3,3$ & $1,2,2,2,1,1$ & 0.66633 & 31 & “" & “" & “" & Grade 3 \\
\hline $1,6,6,6,3,0$ & $1,2,2,2,1,0$ & 0.66630 & 30 & “" & “" & “" & Grade 4 \\
\hline $1,6,6,6,0,9$ & $1,2,2,2,0,3$ & 0.66609 & 758 & “" & Class 2 & Order 4 & Grade 1 \\
\hline $1,6,6,6,0,6$ & $1,2,2,2,0,2$ & 0.66606 & 93 & “" & "6 & “" & Grade 2 \\
\hline $1,6,6,6,0,3$ & $1,2,2,2,0,1$ & 0.66603 & 30 & “" & “" & “" & Grade 3 \\
\hline $1,6,6,6,0,0$ & $1,2,2,2,0,0$ & 0.66600 & 29 & “" & “" & “" & Grade 4 \\
\hline $1,6,6,3,9,9$ & $1,2,2,1,3,3$ & 0.66399 & 986 & Middle & Class 3 & Order 1 & Grade 1 \\
\hline $1,6,6,3,9,6$ & $1,2,2,1,3,2$ & 0.66396 & 321 & “" & "“ & “" & Grade 2 \\
\hline $1,6,6,3,9,3$ & $1,2,2,1,3,1$ & 0.66393 & 258 & “" & “" & “" & Grade 3 \\
\hline $1,6,6,3,9,0$ & $1,2,2,1,3,0$ & 0.66390 & 257 & “" & “" & "“ & Grade 4 \\
\hline $1,6,6,3,6,9$ & $1,2,2,1,2,3$ & 0.66369 & 775 & "“ & Class 3 & Order 2 & Grade 1 \\
\hline $1,6,6,3,6,6$ & $1,2,2,1,2,2$ & 0.66366 & 110 & “" & “" & “" & Grade 2 \\
\hline $1,6,6,3,6,3$ & $1,2,2,1,2,1$ & 0.66363 & 47 & “" & “" & “" & Grade 3 \\
\hline $1,6,6,3,6,0$ & $1,2,2,1,2,0$ & 0.66360 & 46 & “" & “" & "“ & Grade 4 \\
\hline $1,6,6,3,3,9$ & $1,2,2,1,1,3$ & 0.66339 & 744 & “" & Class 3 & Order 3 & Grade 1 \\
\hline $1,6,6,3,3,6$ & $1,2,2,1,1,2$ & 0.66336 & 79 & “" & “" & “" & Grade 2 \\
\hline $1,6,6,3,3,3$ & $1,2,2,1,1,1$ & 0.66333 & 16 & “" & “" & “" & Grade 3 \\
\hline $1,6,6,3,3,0$ & $1,2,2,1,1,0$ & 0.66330 & 15 & “ & “ & “ & Grade 4 \\
\hline $1,6,6,3,0,9$ & $1,2,2,1,0,3$ & 0.66309 & 743 & “" & Class 3 & Order 4 & Grade 1 \\
\hline $1,6,6,3,0,6$ & $1,2,2,1,0,2$ & 0.66306 & 78 & “" & “" & “" & Grade 2 \\
\hline $1,6,6,3,0,3$ & $1,2,2,1,0,1$ & 0.66303 & 15 & “" & “" & “" & Grade 3 \\
\hline $1,6,6,3,0,0$ & $1,2,2,1,0,0$ & 0.66300 & 14 & “" & “" & “" & Grade 4 \\
\hline $1,6,6,0,9,9$ & $1,2,2,0,3,3$ & 0.66099 & 985 & Middle & Class 4 & Order 1 & Grade 1 \\
\hline $1,6,6,0,9,6$ & $1,2,2,0,3,2$ & 0.66096 & 320 & “" & 6 & 66 & Grade 2 \\
\hline $1,6,6,0,9,3$ & $1,2,2,0,3,1$ & 0.66093 & 257 & “" & ") & “" & Grade 3 \\
\hline $1,6,6,0,9,0$ & $1,2,2,0,3,0$ & 0.66090 & 256 & “" & “" & “" & Grade 4 \\
\hline $1,6,6,0,6,9$ & $1,2,2,0,2,3$ & 0.66069 & 774 & “" & Class 4 & Order 2 & Grade 1 \\
\hline $1,6,6,0,6,6$ & $1,2,2,0,2,2$ & 0.66066 & 109 & “" & " & "، & Grade 2 \\
\hline $1,6,6,0,6,3$ & $1,2,2,0,2,1$ & 0.66063 & 46 & “" & “" & “" & Grade 3 \\
\hline $1,6,6,0,6,0$ & $1,2,2,0,2,0$ & 0.66060 & 45 & “" & “" & “" & Grade 4 \\
\hline $1,6,6,0,3,9$ & $1,2,2,0,1,3$ & 0.66039 & 743 & “" & Class 4 & Order 3 & Grade 1 \\
\hline
\end{tabular}


SOCIO-DEMOGRAPHIC STATUS

\begin{tabular}{|c|c|c|c|c|c|c|c|}
\hline $1,6,6,0,3,6$ & $1,2,2,0,1,2$ & 0.66036 & 78 & “" & “" & " & Grade 2 \\
\hline $1,6,6,0,3,3$ & $1,2,2,0,1,1$ & 0.66033 & 15 & “" & “" & “" & Grade 3 \\
\hline $1,6,6,0,3,0$ & $1,2,2,0,1,0$ & 0.66030 & 14 & “" & “" & “" & Grade 4 \\
\hline $1,6,6,0,0,9$ & $1,2,2,0,0,3$ & 0.66009 & 742 & “6 & Class 4 & Order 4 & Grade 1 \\
\hline $1,6,6,0,0,6$ & $1,2,2,0,0,2$ & 0.66006 & 77 & “" & “" & “" & Grade 2 \\
\hline $1,6,6,0,0,3$ & $1,2,2,0,0,1$ & 0.66003 & 14 & “" & “" & “" & Grade 3 \\
\hline $1,6,6,0,0,0$ & $1,2,2,0,0,0$ & 0.66000 & 13 & "“ & “" & “" & Grade 4 \\
\hline $1,6,3,9,9,9$ & $1,2,1,3,3,3$ & 0.63999 & 1059 & Lower & Class 1 & Order 1 & Grade 1 \\
\hline $1,6,3,9,9,6$ & $1,2,1,3,3,2$ & 0.63996 & 394 & “" & “" & “" & Grade 2 \\
\hline $1,6,3,9,9,3$ & $1,2,1,3,3,1$ & 0.63993 & 331 & “" & “" & “" & Grade 3 \\
\hline $1,6,3,9,9,0$ & $1,2,1,3,3,0$ & 0.63990 & 330 & “" & “" & “" & Grade 4 \\
\hline $1,6,3,9,6,9$ & $1,2,1,3,2,3$ & 0.63969 & 848 & “" & Class 1 & Order 2 & Grade 1 \\
\hline $1,6,3,9,6,6$ & $1,2,1,3,2,2$ & 0.63966 & 183 & “" & “" & “" & Grade 2 \\
\hline $1,6,3,9,6,3$ & $1,2,1,3,2,1$ & 0.63963 & 120 & “" & “" & “" & Grade 3 \\
\hline $1,6,3,9,6,0$ & $1,2,1,3,2,0$ & 0.63960 & 119 & “" & "6 & 6 & Grade 4 \\
\hline $1,6,3,9,3,9$ & $1,2,1,3,1,3$ & 0.63939 & 817 & “" & Class 1 & Order 3 & Grade 1 \\
\hline $1,6,3,9,3,6$ & $1,2,1,3,1,2$ & 0.63936 & 152 & “" & “" & "“ & Grade 2 \\
\hline $1,6,3,9,3,3$ & $1,2,1,3,1,1$ & 0.63933 & 89 & “" & “" & “" & Grade 3 \\
\hline $1,6,3,9,3,0$ & $1,2,1,3,1,0$ & 0.63930 & 88 & “" & "“ & " & Grade 4 \\
\hline $1,6,3,9,0,9$ & $1,2,1,3,0,3$ & 0.63909 & 816 & “" & Class 1 & Order 4 & Grade 1 \\
\hline $1,6,3,9,0,6$ & $1,2,1,3,0,2$ & 0.63906 & 151 & “" & “" & "“ & Grade 2 \\
\hline $1,6,3,9,0,3$ & $1,2,1,3,0,1$ & 0.63903 & 88 & "“ & “" & “" & Grade 3 \\
\hline $1,6,3,9,0,0$ & $1,2,1,3,0,0$ & 0.63900 & 87 & “" & “" & “" & Grade 4 \\
\hline $1,6,3,6,9,9$ & $1,2,1,2,3,3$ & 0.63699 & 994 & Lower & Class 2 & Order 1 & Grade 1 \\
\hline $1,6,3,6,9,6$ & $1,2,1,2,3,2$ & 0.63696 & 329 & “" & “" & "“ & Grade 2 \\
\hline $1,6,3,6,9,3$ & $1,2,1,2,3,1$ & 0.63693 & 266 & “" & “" & “" & Grade 3 \\
\hline $1,6,3,6,9,0$ & $1,2,1,2,3,0$ & 0.63690 & 265 & “" & “" & “" & Grade 4 \\
\hline $1,6,3,6,6,9$ & $1,2,1,2,2,3$ & 0.63669 & 783 & “" & Class 2 & Order 2 & Grade 1 \\
\hline $1,6,3,6,6,6$ & $1,2,1,2,2,2$ & 0.63666 & 118 & “" & “" & “" & Grade 2 \\
\hline $1,6,3,6,6,3$ & $1,2,1,2,2,1$ & 0.63663 & 55 & “" & “" & “" & Grade 3 \\
\hline $1,6,3,6,6,0$ & $1,2,1,2,2,0$ & 0.63660 & 54 & “" & “" & “" & Grade 4 \\
\hline $1,6,3,6,3,9$ & $1,2,1,2,1,3$ & 0.63639 & 752 & “" & Class 2 & Order 3 & Grade 1 \\
\hline $1,6,3,6,3,6$ & $1,2,1,2,1,2$ & 0.63636 & 87 & “" & “" & “" & Grade 2 \\
\hline $1,6,3,6,3,3$ & $1,2,1,2,1,1$ & 0.63633 & 24 & “" & “" & “" & Grade 3 \\
\hline $1,6,3,6,3,0$ & $1,2,1,2,1,0$ & 0.63630 & 23 & “" & “" & 66 & Grade 4 \\
\hline $1,6,3,6,0,9$ & $1,2,1,2,0,3$ & 0.63609 & 751 & “" & Class 2 & Order 4 & Grade 1 \\
\hline $1,6,3,6,0,6$ & $1,2,1,2,0,2$ & 0.63606 & 86 & “" & “" & “" & Grade 2 \\
\hline $1,6,3,6,0,3$ & $1,2,1,2,0,1$ & 0.63603 & 23 & “" & “" & “" & Grade 3 \\
\hline $1,6,3,6,0,0$ & $1,2,1,2,0,0$ & 0.63600 & 22 & “" & “" & "، & Grade 4 \\
\hline $1,6,3,3,9,9$ & $1,2,1,1,3,3$ & 0.63399 & 979 & Lower & Class 3 & Order 1 & Grade 1 \\
\hline $1,6,3,3,9,6$ & $1,2,1,1,3,2$ & 0.63396 & 314 & “" & “" & “" & Grade 2 \\
\hline $1,6,3,3,9,3$ & $1,2,1,1,3,1$ & 0.63393 & 251 & “" & “" & “" & Grade 3 \\
\hline
\end{tabular}


SOCIO-DEMOGRAPHIC STATUS

\begin{tabular}{|c|c|c|c|c|c|c|c|}
\hline $1,6,3,3,9,0$ & $1,2,1,1,3,0$ & 0.63390 & 250 & “" & “" & “" & Grade 4 \\
\hline $1,6,3,3,6,9$ & $1,2,1,1,2,3$ & 0.63369 & 768 & “6 & Class 3 & Order 2 & Grade 1 \\
\hline $1,6,3,3,6,6$ & $1,2,1,1,2,2$ & 0.63366 & 103 & “" & “" & “" & Grade 2 \\
\hline $1,6,3,3,6,3$ & $1,2,1,1,2,1$ & 0.63363 & 40 & “" & “" & “" & Grade 3 \\
\hline $1,6,3,3,6,0$ & $1,2,1,1,2,0$ & 0.63360 & 39 & "“ & “" & "“ & Grade 4 \\
\hline $1,6,3,3,3,9$ & $1,2,1,1,1,3$ & 0.63339 & 737 & “" & Class 3 & Order 3 & Grade 1 \\
\hline $1,6,3,3,3,6$ & $1,2,1,1,1,2$ & 0.63336 & 72 & “" & “" & "“ & Grade 2 \\
\hline $1,6,3,3,3,3$ & $1,2,1,1,1,1$ & 0.63333 & 9 & “" & “" & “" & Grade 3 \\
\hline $1,6,3,3,3,0$ & $1,2,1,1,1,0$ & 0.63330 & 8 & “" & “" & "“ & Grade 4 \\
\hline $1,6,3,3,0,9$ & $1,2,1,1,0,3$ & 0.63309 & 736 & “" & Class 3 & Order 4 & Grade 1 \\
\hline $1,6,3,3,0,6$ & $1,2,1,1,0,2$ & 0.63306 & 71 & “" & “" & “" & Grade 2 \\
\hline $1,6,3,3,0,3$ & $1,2,1,1,0,1$ & 0.63303 & 8 & “" & “" & “" & Grade 3 \\
\hline $1,6,3,3,0,0$ & $1,2,1,1,0,0$ & 0.63300 & 7 & “" & “" & “" & Grade 4 \\
\hline $1,6,3,0,9,9$ & $1,2,1,0,3,3$ & 0.63099 & 978 & Lower & Class 4 & Order 1 & Grade 1 \\
\hline $1,6,3,0,9,6$ & $1,2,1,0,3,2$ & 0.63096 & 313 & “" & “" & “" & Grade 2 \\
\hline $1,6,3,0,9,3$ & $1,2,1,0,3,1$ & 0.63093 & 250 & “" & “" & “" & Grade 3 \\
\hline $1,6,3,0,9,0$ & $1,2,1,0,3,0$ & 0.63090 & 249 & “" & “" & “" & Grade 4 \\
\hline $1,6,3,0,6,9$ & $1,2,1,0,2,3$ & 0.63069 & 767 & “" & Class 4 & Order 2 & Grade 1 \\
\hline $1,6,3,0,6,6$ & $1,2,1,0,2,2$ & 0.63066 & 102 & “" & “" & “" & Grade 2 \\
\hline $1,6,3,0,6,3$ & $1,2,1,0,2,1$ & 0.63063 & 39 & “" & “" & “" & Grade 3 \\
\hline $1,6,3,0,6,0$ & $1,2,1,0,2,0$ & 0.63060 & 38 & “" & “" & "“ & Grade 4 \\
\hline $1,6,3,0,3,9$ & $1,2,1,0,1,3$ & 0.63039 & 736 & “" & Class 4 & Order 3 & Grade 1 \\
\hline $1,6,3,0,3,6$ & $1,2,1,0,1,2$ & 0.63036 & 71 & “" & “" & "6 & Grade 2 \\
\hline $1,6,3,0,3,3$ & $1,2,1,0,1,1$ & 0.63033 & 8 & “" & “" & “" & Grade 3 \\
\hline $1,6,3,0,3,0$ & $1,2,1,0,1,0$ & 0.63030 & 7 & “" & “" & “" & Grade 4 \\
\hline $1,6,3,0,0,9$ & $1,2,1,0,0,3$ & 0.63009 & 735 & “" & Class 4 & Order 4 & Grade 1 \\
\hline $1,6,3,0,0,6$ & $1,2,1,0,0,2$ & 0.63006 & 70 & “" & “" & “" & Grade 2 \\
\hline $1,6,3,0,0,3$ & $1,2,1,0,0,1$ & 0.63003 & 7 & “" & “" & “" & Grade 3 \\
\hline $1,6,3,0,0,0$ & $1,2,1,0,0,0$ & 0.63000 & 6 & “6 & “" & “6 & Grade 4 \\
\hline
\end{tabular}


SOCIO-DEMOGRAPHIC STATUS

\section{Appendix III}

Table: Showing the socio-demographic hierarchies within the first socio-demographic clade of feminine socio-demographic kingdom

\begin{tabular}{|c|c|c|c|c|c|c|c|}
\hline (SDP) Ranking & (SDS) Ranking & SDc & SDs & SD-Group & SD-Class & SD-Order & SD-Grade \\
\hline $1,3,9,9,9,9$ & $1,1,3,3,3,3$ & 0.39999 & 1082 & Upper & Class 1 & Order 1 & Grade 1 \\
\hline $1,3,9,9,9,6$ & $1,1,3,3,3,2$ & 0.39996 & 417 & “" & “" & “" & Grade 2 \\
\hline $1,3,9,9,9,3$ & $1,1,3,3,3,1$ & 0.39993 & 354 & “" & “" & “" & Grade 3 \\
\hline $1,3,9,9,9,0$ & $1,1,3,3,3,0$ & 0.39990 & 353 & “" & “" & "“ & Grade 4 \\
\hline $1,3,9,9,6,9$ & $1,1,3,3,2,3$ & 0.39969 & 871 & "6 & Class 1 & Order 2 & Grade 1 \\
\hline $1,3,9,9,6,6$ & $1,1,3,3,2,2$ & 0.39966 & 206 & “" & “" & “" & Grade 2 \\
\hline $1,3,9,9,6,3$ & $1,1,3,3,2,1$ & 0.39963 & 143 & “" & “" & “" & Grade 3 \\
\hline $1,3,9,9,6,0$ & $1,1,3,3,2,0$ & 0.39960 & 142 & “" & “" & “" & Grade 4 \\
\hline $1,3,9,9,3,9$ & $1,1,3,3,1,3$ & 0.39939 & 840 & “" & Class 1 & Order 3 & Grade 1 \\
\hline $1,3,9,9,3,6$ & $1,1,3,3,1,2$ & 0.39936 & 175 & “" & “" & " & Grade 2 \\
\hline $1,3,9,9,3,3$ & $1,1,3,3,1,1$ & 0.39933 & 112 & “6 & “6 & “6 & Grade 3 \\
\hline $1,3,9,9,3,0$ & $1,1,3,3,1,0$ & 0.39930 & 111 & “" & “" & “" & Grade 4 \\
\hline $1,3,9,9,0,9$ & $1,1,3,3,0,3$ & 0.39909 & 839 & “" & Class 1 & Order 4 & Grade 1 \\
\hline $1,3,9,9,0,6$ & $1,1,3,3,0,2$ & 0.39906 & 174 & “" & “" & “" & Grade 2 \\
\hline $1,3,9,9,0,3$ & $1,1,3,3,0,1$ & 0.39903 & 111 & “" & “" & “" & Grade 3 \\
\hline $1,3,9,9,0,0$ & $1,1,3,3,0,0$ & 0.39900 & 110 & “" & “" & “" & Grade 4 \\
\hline $1,3,9,6,9,9$ & $1,1,3,2,3,3$ & 0.39699 & 1017 & Upper & Class 2 & Order 1 & Grade 1 \\
\hline $1,3,9,6,9,6$ & $1,1,3,2,3,2$ & 0.39696 & 352 & " & “" & "“ & Grade 2 \\
\hline $1,3,9,6,9,3$ & $1,1,3,2,3,1$ & 0.39693 & 289 & “" & “" & " & Grade 3 \\
\hline $1,3,9,6,9,0$ & $1,1,3,2,3,0$ & 0.39690 & 288 & “" & “" & “ & Grade 4 \\
\hline $1,3,9,6,6,9$ & $1,1,3,2,2,3$ & 0.39669 & 806 & “" & Class 2 & Order 2 & Grade 1 \\
\hline $1,3,9,6,6,6$ & $1,1,3,2,2,2$ & 0.39666 & 141 & " & “" & "“ & Grade 2 \\
\hline $1,3,9,6,6,3$ & $1,1,3,2,2,1$ & 0.39663 & 78 & "6 & “6 & “" & Grade 3 \\
\hline $1,3,9,6,6,0$ & $1,1,3,2,2,0$ & 0.39660 & 77 & “ & “" & “ & Grade 4 \\
\hline $1,3,9,6,3,9$ & $1,1,3,2,1,3$ & 0.39639 & 775 & “" & Class 2 & Order 3 & Grade 1 \\
\hline $1,3,9,6,3,6$ & $1,1,3,2,1,2$ & 0.39636 & 110 & “" & “" & “" & Grade 2 \\
\hline $1,3,9,6,3,3$ & $1,1,3,2,1,1$ & 0.39633 & 47 & “" & “" & “" & Grade 3 \\
\hline $1,3,9,6,3,0$ & $1,1,3,2,1,0$ & 0.39630 & 46 & “ & “ & “" & Grade 4 \\
\hline $1,3,9,6,0,9$ & $1,1,3,2,0,3$ & 0.39609 & 774 & “" & Class 2 & Order 4 & Grade 1 \\
\hline $1,3,9,6,0,6$ & $1,1,3,2,0,2$ & 0.39606 & 109 & “" & “" & “" & Grade 2 \\
\hline $1,3,9,6,0,3$ & $1,1,3,2,0,1$ & 0.39603 & 46 & “" & “" & “" & Grade 3 \\
\hline $1,3,9,6,0,0$ & $1,1,3,2,0,0$ & 0.39600 & 45 & “ & “" & “" & Grade 4 \\
\hline $1,3,9,3,9,9$ & $1,1,3,1,3,3$ & 0.39399 & 1002 & Upper & Class 3 & Order 1 & Grade 1 \\
\hline $1,3,9,3,9,6$ & $1,1,3,1,3,2$ & 0.39396 & 337 & “" & “" & “" & Grade 2 \\
\hline $1,3,9,3,9,3$ & $1,1,3,1,3,1$ & 0.39393 & 274 & “" & “" & “" & Grade 3 \\
\hline $1,3,9,3,9,0$ & $1,1,3,1,3,0$ & 0.39390 & 273 & " & “" & “" & Grade 4 \\
\hline $1,3,9,3,6,9$ & $1,1,3,1,2,3$ & 0.39369 & 791 & “" & Class 3 & Order 2 & Grade 1 \\
\hline
\end{tabular}


SOCIO-DEMOGRAPHIC STATUS

\begin{tabular}{|c|c|c|c|c|c|c|c|}
\hline $1,3,9,3,6,6$ & $1,1,3,1,2,2$ & 0.39366 & 126 & " & “" & " & Grade 2 \\
\hline $1,3,9,3,6,3$ & $1,1,3,1,2,1$ & 0.39363 & 63 & “" & “" & “" & Grade 3 \\
\hline $1,3,9,3,6,0$ & $1,1,3,1,2,0$ & 0.39360 & 62 & “" & “" & “" & Grade 4 \\
\hline $1,3,9,3,3,9$ & $1,1,3,1,1,3$ & 0.39339 & 760 & “6 & Class 3 & Order 3 & Grade 1 \\
\hline $1,3,9,3,3,6$ & $1,1,3,1,1,2$ & 0.39336 & 95 & " & “" & “" & Grade 2 \\
\hline $1,3,9,3,3,3$ & $1,1,3,1,1,1$ & 0.39333 & 32 & " & “" & “" & Grade 3 \\
\hline $1,3,9,3,3,0$ & $1,1,3,1,1,0$ & 0.39330 & 31 & “" & “" & “" & Grade 4 \\
\hline $1,3,9,3,0,9$ & $1,1,3,1,0,3$ & 0.39309 & 759 & “" & Class 3 & Order 4 & Grade 1 \\
\hline $1,3,9,3,0,6$ & $1,1,3,1,0,2$ & 0.39306 & 94 & " & “" & “" & Grade 2 \\
\hline $1,3,9,3,0,3$ & $1,1,3,1,0,1$ & 0.39303 & 31 & “" & “" & “" & Grade 3 \\
\hline $1,3,9,3,0,0$ & $1,1,3,1,0,0$ & 0.39300 & 30 & “" & “" & “" & Grade 4 \\
\hline $1,3,9,0,9,9$ & $1,1,3,0,3,3$ & 0.39099 & 1001 & Upper & Class 4 & Order 1 & Grade 1 \\
\hline $1,3,9,0,9,6$ & $1,1,3,0,3,2$ & 0.39096 & 336 & “ & “" & “" & Grade 2 \\
\hline $1,3,9,0,9,3$ & $1,1,3,0,3,1$ & 0.39093 & 273 & “" & “" & “" & Grade 3 \\
\hline $1,3,9,0,9,0$ & $1,1,3,0,3,0$ & 0.39090 & 272 & 6 & "6 & 6 & Grade 4 \\
\hline $1,3,9,0,6,9$ & $1,1,3,0,2,3$ & 0.39069 & 790 & “" & Class 4 & Order 2 & Grade 1 \\
\hline $1,3,9,0,6,6$ & $1,1,3,0,2,2$ & 0.39066 & 125 & “" & “" & “" & Grade 2 \\
\hline $1,3,9,0,6,3$ & $1,1,3,0,2,1$ & 0.39063 & 62 & “" & “" & “" & Grade 3 \\
\hline $1,3,9,0,6,0$ & $1,1,3,0,2,0$ & 0.39060 & 61 & “" & “" & “" & Grade 4 \\
\hline $1,3,9,0,3,9$ & $1,1,3,0,1,3$ & 0.39039 & 759 & “" & Class 4 & Order 3 & Grade 1 \\
\hline $1,3,9,0,3,6$ & $1,1,3,0,1,2$ & 0.39036 & 94 & “" & “" & “" & Grade 2 \\
\hline $1,3,9,0,3,3$ & $1,1,3,0,1,1$ & 0.39033 & 31 & “" & “" & “" & Grade 3 \\
\hline $1,3,9,0,3,0$ & $1,1,3,0,1,0$ & 0.39030 & 30 & “" & “" & “" & Grade 4 \\
\hline $1,3,9,0,0,9$ & $1,1,3,0,0,3$ & 0.39009 & 758 & “" & Class 4 & Order 4 & Grade 1 \\
\hline $1,3,9,0,0,6$ & $1,1,3,0,0,2$ & 0.39006 & 93 & “" & “" & “" & Grade 2 \\
\hline $1,3,9,0,0,3$ & $1,1,3,0,0,1$ & 0.39003 & 30 & “" & “" & “" & Grade 3 \\
\hline $1,3,9,0,0,0$ & $1,1,3,0,0,0$ & 0.39000 & 29 & “" & “" & “" & Grade 4 \\
\hline $1,3,6,9,9,9$ & $1,1,2,3,3,3$ & 0.36999 & 1063 & Middle & Class 1 & Order 1 & Grade 1 \\
\hline $1,3,6,9,9,6$ & $1,1,2,3,3,2$ & 0.36996 & 398 & “" & “" & “" & Grade 2 \\
\hline $1,3,6,9,9,3$ & $1,1,2,3,3,1$ & 0.36993 & 335 & “" & “ & “" & Grade 3 \\
\hline $1,3,6,9,9,0$ & $1,1,2,3,3,0$ & 0.36990 & 334 & “" & “" & “" & Grade 4 \\
\hline $1,3,6,9,6,9$ & $1,1,2,3,2,3$ & 0.36969 & 852 & “" & Class 1 & Order 2 & Grade 1 \\
\hline $1,3,6,9,6,6$ & $1,1,2,3,2,2$ & 0.36966 & 187 & “" & “" & “" & Grade 2 \\
\hline $1,3,6,9,6,3$ & $1,1,2,3,2,1$ & 0.36963 & 124 & “" & “ & “" & Grade 3 \\
\hline $1,3,6,9,6,0$ & $1,1,2,3,2,0$ & 0.36960 & 123 & “" & “" & "6 & Grade 4 \\
\hline $1,3,6,9,3,9$ & $1,1,2,3,1,3$ & 0.36939 & 821 & “" & Class 1 & Order 3 & Grade 1 \\
\hline $1,3,6,9,3,6$ & $1,1,2,3,1,2$ & 0.36936 & 156 & “" & “" & “ & Grade 2 \\
\hline $1,3,6,9,3,3$ & $1,1,2,3,1,1$ & 0.36933 & 93 & “" & “" & “" & Grade 3 \\
\hline $1,3,6,9,3,0$ & $1,1,2,3,1,0$ & 0.36930 & 92 & “" & “" & "، & Grade 4 \\
\hline $1,3,6,9,0,9$ & $1,1,2,3,0,3$ & 0.36909 & 820 & “" & Class 1 & Order 4 & Grade 1 \\
\hline $1,3,6,9,0,6$ & $1,1,2,3,0,2$ & 0.36906 & 155 & “" & “" & “" & Grade 2 \\
\hline $1,3,6,9,0,3$ & $1,1,2,3,0,1$ & 0.36903 & 92 & “" & “" & “" & Grade 3 \\
\hline
\end{tabular}


SOCIO-DEMOGRAPHIC STATUS

\begin{tabular}{|c|c|c|c|c|c|c|c|}
\hline $1,3,6,9,0,0$ & $1,1,2,3,0,0$ & 0.36900 & 91 & “" & “" & “" & Grade 4 \\
\hline $1,3,6,6,9,9$ & $1,1,2,2,3,3$ & 0.36699 & 998 & Middle & Class 2 & Order 1 & Grade 1 \\
\hline $1,3,6,6,9,6$ & $1,1,2,2,3,2$ & 0.36696 & 333 & “" & “" & “" & Grade 2 \\
\hline $1,3,6,6,9,3$ & $1,1,2,2,3,1$ & 0.36693 & 270 & “" & “" & “" & Grade 3 \\
\hline $1,3,6,6,9,0$ & $1,1,2,2,3,0$ & 0.36690 & 269 & “" & 6 & 6 & Grade 4 \\
\hline $1,3,6,6,6,9$ & $1,1,2,2,2,3$ & 0.36669 & 787 & “" & Class 2 & Order 2 & Grade 1 \\
\hline $1,3,6,6,6,6$ & $1,1,2,2,2,2$ & 0.36666 & 122 & “" & “" & “" & Grade 2 \\
\hline $1,3,6,6,6,3$ & $1,1,2,2,2,1$ & 0.36663 & 59 & “" & “" & “" & Grade 3 \\
\hline $1,3,6,6,6,0$ & $1,1,2,2,2,0$ & 0.36660 & 58 & “" & “" & “" & Grade 4 \\
\hline $1,3,6,6,3,9$ & $1,1,2,2,1,3$ & 0.36639 & 756 & “" & Class 2 & Order 3 & Grade 1 \\
\hline $1,3,6,6,3,6$ & $1,1,2,2,1,2$ & 0.36636 & 91 & “" & “" & “" & Grade 2 \\
\hline $1,3,6,6,3,3$ & $1,1,2,2,1,1$ & 0.36633 & 28 & “" & “" & “" & Grade 3 \\
\hline $1,3,6,6,3,0$ & $1,1,2,2,1,0$ & 0.36630 & 27 & “" & “" & “" & Grade 4 \\
\hline $1,3,6,6,0,9$ & $1,1,2,2,0,3$ & 0.36609 & 755 & “" & Class 2 & Order 4 & Grade 1 \\
\hline $1,3,6,6,0,6$ & $1,1,2,2,0,2$ & 0.36606 & 90 & “" & “" & “" & Grade 2 \\
\hline $1,3,6,6,0,3$ & $1,1,2,2,0,1$ & 0.36603 & 27 & “" & "6 & "، & Grade 3 \\
\hline $1,3,6,6,0,0$ & $1,1,2,2,0,0$ & 0.36600 & 26 & “" & "“ & "، & Grade 4 \\
\hline $1,3,6,3,9,9$ & $1,1,2,1,3,3$ & 0.36399 & 983 & Middle & Class 3 & Order 1 & Grade 1 \\
\hline $1,3,6,3,9,6$ & $1,1,2,1,3,2$ & 0.36396 & 318 & “" & " & "، & Grade 2 \\
\hline $1,3,6,3,9,3$ & $1,1,2,1,3,1$ & 0.36393 & 255 & “" & "، & “" & Grade 3 \\
\hline $1,3,6,3,9,0$ & $1,1,2,1,3,0$ & 0.36390 & 254 & " & "“ & "، & Grade 4 \\
\hline $1,3,6,3,6,9$ & $1,1,2,1,2,3$ & 0.36369 & 772 & “" & Class 3 & Order 2 & Grade 1 \\
\hline $1,3,6,3,6,6$ & $1,1,2,1,2,2$ & 0.36366 & 107 & “" & “" & “" & Grade 2 \\
\hline $1,3,6,3,6,3$ & $1,1,2,1,2,1$ & 0.36363 & 44 & "6 & ، & ، & Grade 3 \\
\hline $1,3,6,3,6,0$ & $1,1,2,1,2,0$ & 0.36360 & 43 & " & "6 & "6 & Grade 4 \\
\hline $1,3,6,3,3,9$ & $1,1,2,1,1,3$ & 0.36339 & 741 & “" & Class 3 & Order 3 & Grade 1 \\
\hline $1,3,6,3,3,6$ & $1,1,2,1,1,2$ & 0.36336 & 76 & “" & “" & “" & Grade 2 \\
\hline $1,3,6,3,3,3$ & $1,1,2,1,1,1$ & 0.36333 & 13 & “" & 6" & "، & Grade 3 \\
\hline $1,3,6,3,3,0$ & $1,1,2,1,1,0$ & 0.36330 & 12 & “6 & “6 & “6 & Grade 4 \\
\hline $1,3,6,3,0,9$ & $1,1,2,1,0,3$ & 0.36309 & 740 & “" & Class 3 & Order 4 & Grade 1 \\
\hline $1,3,6,3,0,6$ & $1,1,2,1,0,2$ & 0.36306 & 75 & “" & “" & “" & Grade 2 \\
\hline $1,3,6,3,0,3$ & $1,1,2,1,0,1$ & 0.36303 & 12 & “ & " & “" & Grade 3 \\
\hline $1,3,6,3,0,0$ & $1,1,2,1,0,0$ & 0.36300 & 11 & “6 & “6 & “6 & Grade 4 \\
\hline $1,3,6,0,9,9$ & $1,1,2,0,3,3$ & 0.36099 & 982 & Middle & Class 4 & Order 1 & Grade 1 \\
\hline $1,3,6,0,9,6$ & $1,1,2,0,3,2$ & 0.36096 & 317 & “" & “" & "، & Grade 2 \\
\hline $1,3,6,0,9,3$ & $1,1,2,0,3,1$ & 0.36093 & 254 & ") & "6 & "ब & Grade 3 \\
\hline $1,3,6,0,9,0$ & $1,1,2,0,3,0$ & 0.36090 & 253 & “" & “" & “" & Grade 4 \\
\hline $1,3,6,0,6,9$ & $1,1,2,0,2,3$ & 0.36069 & 771 & “" & Class 4 & Order 2 & Grade 1 \\
\hline $1,3,6,0,6,6$ & $1,1,2,0,2,2$ & 0.36066 & 106 & “" & “" & “" & Grade 2 \\
\hline $1,3,6,0,6,3$ & $1,1,2,0,2,1$ & 0.36063 & 43 & “" & "6 & "6 & Grade 3 \\
\hline $1,3,6,0,6,0$ & $1,1,2,0,2,0$ & 0.36060 & 42 & “" & “ & “" & Grade 4 \\
\hline $1,3,6,0,3,9$ & $1,1,2,0,1,3$ & 0.36039 & 740 & “" & Class 4 & Order 3 & Grade 1 \\
\hline
\end{tabular}


SOCIO-DEMOGRAPHIC STATUS

\begin{tabular}{|c|c|c|c|c|c|c|c|}
\hline $1,3,6,0,3,6$ & $1,1,2,0,1,2$ & 0.36036 & 75 & " & “" & " & Grade 2 \\
\hline $1,3,6,0,3,3$ & $1,1,2,0,1,1$ & 0.36033 & 12 & “" & “" & “" & Grade 3 \\
\hline $1,3,6,0,3,0$ & $1,1,2,0,1,0$ & 0.36030 & 11 & “" & “" & “" & Grade 4 \\
\hline $1,3,6,0,0,9$ & $1,1,2,0,0,3$ & 0.36009 & 739 & “6 & Class 4 & Order 4 & Grade 1 \\
\hline $1,3,6,0,0,6$ & $1,1,2,0,0,2$ & 0.36006 & 74 & “" & “" & “" & Grade 2 \\
\hline $1,3,6,0,0,3$ & $1,1,2,0,0,1$ & 0.36003 & 11 & " & “" & “" & Grade 3 \\
\hline $1,3,6,0,0,0$ & $1,1,2,0,0,0$ & 0.36000 & 10 & “" & “" & “" & Grade 4 \\
\hline $1,3,3,9,9,9$ & $1,1,1,3,3,3$ & 0.33999 & 1056 & Lower & Class 1 & Order 1 & Grade 1 \\
\hline $1,3,3,9,9,6$ & $1,1,1,3,3,2$ & 0.33996 & 391 & “" & “" & “" & Grade 2 \\
\hline $1,3,3,9,9,3$ & $1,1,1,3,3,1$ & 0.33993 & 328 & “" & “" & “" & Grade 3 \\
\hline $1,3,3,9,9,0$ & $1,1,1,3,3,0$ & 0.33990 & 327 & “" & “" & “" & Grade 4 \\
\hline $1,3,3,9,6,9$ & $1,1,1,3,2,3$ & 0.33969 & 845 & “" & Class 1 & Order 2 & Grade 1 \\
\hline $1,3,3,9,6,6$ & $1,1,1,3,2,2$ & 0.33966 & 180 & “" & “" & “" & Grade 2 \\
\hline $1,3,3,9,6,3$ & $1,1,1,3,2,1$ & 0.33963 & 117 & “" & “" & “" & Grade 3 \\
\hline $1,3,3,9,6,0$ & $1,1,1,3,2,0$ & 0.33960 & 116 & 6 & "6 & 6 & Grade 4 \\
\hline $1,3,3,9,3,9$ & $1,1,1,3,1,3$ & 0.33939 & 814 & “" & Class 1 & Order 3 & Grade 1 \\
\hline $1,3,3,9,3,6$ & $1,1,1,3,1,2$ & 0.33936 & 149 & “" & “" & “" & Grade 2 \\
\hline $1,3,3,9,3,3$ & $1,1,1,3,1,1$ & 0.33933 & 86 & “" & “ & “" & Grade 3 \\
\hline $1,3,3,9,3,0$ & $1,1,1,3,1,0$ & 0.33930 & 85 & “" & “" & " & Grade 4 \\
\hline $1,3,3,9,0,9$ & $1,1,1,3,0,3$ & 0.33909 & 813 & “" & Class 1 & Order 4 & Grade 1 \\
\hline $1,3,3,9,0,6$ & $1,1,1,3,0,2$ & 0.33906 & 148 & “" & “" & “" & Grade 2 \\
\hline $1,3,3,9,0,3$ & $1,1,1,3,0,1$ & 0.33903 & 85 & “" & “" & “" & Grade 3 \\
\hline $1,3,3,9,0,0$ & $1,1,1,3,0,0$ & 0.33900 & 84 & “" & “" & “" & Grade 4 \\
\hline $1,3,3,6,9,9$ & $1,1,1,2,3,3$ & 0.33699 & 991 & Lower & Class 2 & Order 1 & Grade 1 \\
\hline $1,3,3,6,9,6$ & $1,1,1,2,3,2$ & 0.33696 & 326 & “" & “" & “" & Grade 2 \\
\hline $1,3,3,6,9,3$ & $1,1,1,2,3,1$ & 0.33693 & 263 & “" & “" & “" & Grade 3 \\
\hline $1,3,3,6,9,0$ & $1,1,1,2,3,0$ & 0.33690 & 262 & “" & “" & “" & Grade 4 \\
\hline $1,3,3,6,6,9$ & $1,1,1,2,2,3$ & 0.33669 & 780 & “" & Class 2 & Order 2 & Grade 1 \\
\hline $1,3,3,6,6,6$ & $1,1,1,2,2,2$ & 0.33666 & 115 & “" & “" & “" & Grade 2 \\
\hline $1,3,3,6,6,3$ & $1,1,1,2,2,1$ & 0.33663 & 52 & “" & “ & “" & Grade 3 \\
\hline $1,3,3,6,6,0$ & $1,1,1,2,2,0$ & 0.33660 & 51 & “" & “" & “" & Grade 4 \\
\hline $1,3,3,6,3,9$ & $1,1,1,2,1,3$ & 0.33639 & 749 & “" & Class 2 & Order 3 & Grade 1 \\
\hline $1,3,3,6,3,6$ & $1,1,1,2,1,2$ & 0.33636 & 84 & “" & “" & “" & Grade 2 \\
\hline $1,3,3,6,3,3$ & $1,1,1,2,1,1$ & 0.33633 & 21 & “" & “ & “" & Grade 3 \\
\hline $1,3,3,6,3,0$ & $1,1,1,2,1,0$ & 0.33630 & 20 & “" & “" & "6 & Grade 4 \\
\hline $1,3,3,6,0,9$ & $1,1,1,2,0,3$ & 0.33609 & 748 & “" & Class 2 & Order 4 & Grade 1 \\
\hline $1,3,3,6,0,6$ & $1,1,1,2,0,2$ & 0.33606 & 83 & “" & “" & “" & Grade 2 \\
\hline $1,3,3,6,0,3$ & $1,1,1,2,0,1$ & 0.33603 & 20 & “" & “" & “" & Grade 3 \\
\hline $1,3,3,6,0,0$ & $1,1,1,2,0,0$ & 0.33600 & 19 & “" & “" & "، & Grade 4 \\
\hline $1,3,3,3,9,9$ & $1,1,1,1,3,3$ & 0.33399 & 976 & Lower & Class 3 & Order 1 & Grade 1 \\
\hline $1,3,3,3,9,6$ & $1,1,1,1,3,2$ & 0.33396 & 311 & “" & “" & “" & Grade 2 \\
\hline $1,3,3,3,9,3$ & $1,1,1,1,3,1$ & 0.33393 & 248 & “" & “" & “" & Grade 3 \\
\hline
\end{tabular}


SOCIO-DEMOGRAPHIC STATUS

\begin{tabular}{|c|c|c|c|c|c|c|c|}
\hline $1,3,3,3,9,0$ & $1,1,1,1,3,0$ & 0.33390 & 247 & “6 & "6 & “6 & Grade 4 \\
\hline $1,3,3,3,6,9$ & $1,1,1,1,2,3$ & 0.33369 & 765 & “6 & Class 3 & Order 2 & Grade 1 \\
\hline $1,3,3,3,6,6$ & $1,1,1,1,2,2$ & 0.33366 & 100 & “ & “ & “ & Grade 2 \\
\hline $1,3,3,3,6,3$ & $1,1,1,1,2,1$ & 0.33363 & 37 & “" & “" & “" & Grade 3 \\
\hline $1,3,3,3,6,0$ & $1,1,1,1,2,0$ & 0.33360 & 36 & “" & “" & “" & Grade 4 \\
\hline $1,3,3,3,3,9$ & $1,1,1,1,1,3$ & 0.33339 & 734 & "6 & Class 3 & Order 3 & Grade 1 \\
\hline $1,3,3,3,3,6$ & $1,1,1,1,1,2$ & 0.33336 & 69 & “" & “" & “" & Grade 2 \\
\hline $1,3,3,3,3,3$ & $1,1,1,1,1,1$ & 0.33333 & 6 & “" & “" & " & Grade 3 \\
\hline $1,3,3,3,3,0$ & $1,1,1,1,1,0$ & 0.33330 & 5 & “" & “" & "“ & Grade 4 \\
\hline $1,3,3,3,0,9$ & $1,1,1,1,0,3$ & 0.33309 & 733 & “" & Class 3 & Order 4 & Grade 1 \\
\hline $1,3,3,3,0,6$ & $1,1,1,1,0,2$ & 0.33306 & 68 & “ & “ & “ & Grade 2 \\
\hline $1,3,3,3,0,3$ & $1,1,1,1,0,1$ & 0.33303 & 5 & “" & "“ & "“ & Grade 3 \\
\hline $1,3,3,3,0,0$ & $1,1,1,1,0,0$ & 0.33300 & 4 & “" & “" & ") & Grade 4 \\
\hline $1,3,3,0,9,9$ & $1,1,1,0,3,3$ & 0.33099 & 975 & Lower & Class 4 & Order 1 & Grade 1 \\
\hline $1,3,3,0,9,6$ & $1,1,1,0,3,2$ & 0.33096 & 310 & “" & “" & “" & Grade 2 \\
\hline $1,3,3,0,9,3$ & $1,1,1,0,3,1$ & 0.33093 & 247 & “" & ") & "ब & Grade 3 \\
\hline $1,3,3,0,9,0$ & $1,1,1,0,3,0$ & 0.33090 & 246 & “" & "6 & "“ & Grade 4 \\
\hline $1,3,3,0,6,9$ & $1,1,1,0,2,3$ & 0.33069 & 764 & “" & Class 4 & Order 2 & Grade 1 \\
\hline $1,3,3,0,6,6$ & $1,1,1,0,2,2$ & 0.33066 & 99 & “ & “ & “ & Grade 2 \\
\hline $1,3,3,0,6,3$ & $1,1,1,0,2,1$ & 0.33063 & 36 & “" & “" & “" & Grade 3 \\
\hline $1,3,3,0,6,0$ & $1,1,1,0,2,0$ & 0.33060 & 35 & “" & “" & “" & Grade 4 \\
\hline $1,3,3,0,3,9$ & $1,1,1,0,1,3$ & 0.33039 & 733 & “ & Class 4 & Order 3 & Grade 1 \\
\hline $1,3,3,0,3,6$ & $1,1,1,0,1,2$ & 0.33036 & 68 & “ & “" & “" & Grade 2 \\
\hline $1,3,3,0,3,3$ & $1,1,1,0,1,1$ & 0.33033 & 5 & “" & "، & " & Grade 3 \\
\hline $1,3,3,0,3,0$ & $1,1,1,0,1,0$ & 0.33030 & 4 & “" & “" & “ & Grade 4 \\
\hline $1,3,3,0,0,9$ & $1,1,1,0,0,3$ & 0.33009 & 732 & “" & Class 4 & Order 4 & Grade 1 \\
\hline $1,3,3,0,0,6$ & $1,1,1,0,0,2$ & 0.33006 & 67 & “" & “" & “" & Grade 2 \\
\hline $1,3,3,0,0,3$ & $1,1,1,0,0,1$ & 0.33003 & 4 & “" & “" & “" & Grade 3 \\
\hline $1,3,3,0,0,0$ & $1,1,1,0,0,0$ & 0.33000 & 3 & “" & “" & “" & Grade 4 \\
\hline
\end{tabular}

Conflicts of Interest: The author declares no conflict of interest. This research did not receive any specific grant from funding agencies in the public, commercial, or not-for-profit sectors.

Correspondence: Correspondence should be address to Kabir Bindawa Abdullahi, Department of Biology, Faculty of Natural and Applied Sciences, Umaru Musa Yar'adua University, P.M.B., 2218 Katsina, Katsina State, Nigeria. 
SOCIO-DEMOGRAPHIC STATUS

\section{References}

Abdullahi, K.B. (2019). Optimization of Value Measurement Methods. Preprints, 2019010107, page 21-23. doi: 10.20944/preprints201901.0107.v2.

Bai, P.Y., Wittert, G.A., Taylor, A.W., Martin, S.A., Milne, R.W., Shi, Z. (2015). The Association of Socio-Demographic Status, Lifestyle Factors and Dietary Patterns with Total Urinary Phthalates in Australian Men, PLoS ONE, 10(4), e0122140. https://doi.org/10.1371/journal.pone.0122140

Karl, M. (1959). Capital: An Analysis of Capitalist Production. Volume 1, Moscow, p. 332.

Kravdal, ̌̌. (2002). A cancer survival model that takes sociodemographic variations in "normal" mortality into account: comparison with other models. J Epidemiol Commun Health, 56, 309-18.

Ramirez, A.J., Pinder, K.L., Black, M.E., Richards, M.A., Gregory, W.M., Rubens, R.D. (1993). Psychiatric disorders in patients with advanced breast cancer: prevalence and associated factors. Eur J Cancer, 29, 524-7.

Skrzypczak, M., Łaski, P., Czerniak, U., Kycler, W. (2009). Do chronological age and selected socio-demographic factors affect quality of life in females with breast cancer? Anthr Rev., 72, $31-44$.

Thomas, G., Keltner, D., Nisbett, R. E. (2006). Social psychology. W.W. Norton. pp. 467-468.

Trent, K., \& South, S. J. (1992). Sociodemographic status, parental background, childhood family structure, and attitudes toward family formation. Journal of Marriage and the Family, 54(2), 427-439. http://dx.doi.org/10.2307/353074.

Weber, M. (1921/2015). "Classes, Stände, Parties" in Weber's Rationalism and Modern Society: New Translations on Politics, Bureaucracy and Social Stratification. Edited and Translated by Tony Waters and Dagmar Waters, pp. 37-58. 